\title{
ERS statement on respiratory muscle testing at rest and during exercise
}

\author{
Pierantonio Laveneziana ${ }^{1,2,34}$, Andre Albuquerque ${ }^{3,4}$, Andrea Aliverti ${ }^{5}$, Tony Babb 6 , \\ Esther Barreiro ${ }^{7}$, Martin Dres ${ }^{1,8}$, Bruno-Pierre Dubé ${ }^{9,10}$, Brigitte Fauroux ${ }^{11}$, \\ Joaquim Gea ${ }^{12}$, Jordan A. Guenette ${ }^{13,14}$, Anna L. Hudson ${ }^{15}$, Hans-Joachim Kabitz ${ }^{16}$, \\ Franco Laghi ${ }^{17,18}$, Daniel Langer ${ }^{19,20}$, Yuan-Ming Luo ${ }^{21}$, J. Alberto Neder ${ }^{22}$, \\ Denis O'Donnell ${ }^{23}$, Michael I. Polkey ${ }^{24}$, Roberto A. Rabinovich ${ }^{25,26}$, Andrea Rossi ${ }^{27}$, \\ Frédéric Series $^{28}$, Thomas Similowski ${ }^{1,8}$, Christina M. Spengler ${ }^{29}$, \\ loannis Vogiatzis ${ }^{30,31,32}$ and Samuel Verges ${ }^{33,34}$
}

@ERSpublications

Diverse methods are available for assessment of the respiratory muscles; the technique used should be tailored to the question posed http://ow.ly/poE830o8y58

Cite this article as: Laveneziana $\mathrm{P}$, Albuquerque A, Aliverti A, et al. ERS statement on respiratory muscle testing at rest and during exercise. Eur Respir J 2019; 53: 1801214 [https://doi.org/10.1183/13993003.012142018].

ABSTRACT Assessing respiratory mechanics and muscle function is critical for both clinical practice and research purposes. Several methodological developments over the past two decades have enhanced our understanding of respiratory muscle function and responses to interventions across the spectrum of health and disease. They are especially useful in diagnosing, phenotyping and assessing treatment efficacy in patients with respiratory symptoms and neuromuscular diseases. Considerable research has been undertaken over the past 17 years, since the publication of the previous American Thoracic Society (ATS)/ European Respiratory Society (ERS) statement on respiratory muscle testing in 2002. Key advances have been made in the field of mechanics of breathing, respiratory muscle neurophysiology (electromyography, electroencephalography and transcranial magnetic stimulation) and on respiratory muscle imaging (ultrasound, optoelectronic plethysmography and structured light plethysmography). Accordingly, this ERS task force reviewed the field of respiratory muscle testing in health and disease, with particular reference to data obtained since the previous ATS/ERS statement. It summarises the most recent scientific and methodological developments regarding respiratory mechanics and respiratory muscle assessment by addressing the validity, precision, reproducibility, prognostic value and responsiveness to interventions of various methods. A particular emphasis is placed on assessment during exercise, which is a useful condition to stress the respiratory system.

Published online June 13, 2019; republished July 17, 2019 with amendments to an author's forenames (C.M. Spengler).

This article has supplementary material available from erj.ersjournals.com

This statement was endorsed by the European Respiratory Society Executive Committee on March 5, 2019.

Received: June 292018 | Accepted after revision: Feb 182019

Copyright OERS 2019 
Introduction

Methods

Section 1. Respiratory muscle function

Andrea Albuquerque, Tony Babb, Martin Dres, Brigitte Fauroux, Jordan A. Guenette, Hans Joachim Kabitz, Franco Laghi, Daniel Langer, Pierantonio Laveneziana, J. Alberto Neder, Denis O'Donnell, Mickael I. Polkey,

Andrea Rossi, Christina M. Spengler, Samuel Verges

1.1. Airway opening, oesophageal and gastric pressures: technical considerations

1.1.1. Pressure measurement

1.1.2. Pressure assessment devices

1.1.2.1. Pressure transducers

1.1.2.2. Probes for invasive pressure assessment

1.1.2.3. Devices for measurement of airway opening pressure

1.2. Voluntary tests of respiratory muscle strength

1.2.1. Maximal static inspiratory and expiratory mouth pressure

1.2.2. Maximal sniff nasal inspiratory pressure

1.2.3. Peak cough flow

1.3. Voluntary manoeuvres with oesophageal and gastric pressures

1.4. Respiratory muscle-related mechanics of breathing

1.4.1. Lung function testing

1.4.2. Indices of respiratory muscle effort

1.5. Evoked manoeuvres

1.6. Respiratory muscle endurance testing

1.6.1. Maximal incremental load testing

1.6.2. Constant load testing

1.6.3. Time trial

Section 2. Respiratory muscle neurophysiology

Martin Dres, Anna L. Hudson, Franco Laghi, Yuan-Ming Luo, Andrea Rossi, Frédéric Series, Thomas Similowski

2.1. Electromyography

2.2. Electroencephalography

2.3. Transcranial magnetic stimulation

Section 3. Respiratory muscle imaging

Andrea Aliverti, Martin Dres, Bruno-Pierre Dubé, Brigitte Fauroux, Franco Laghi, Andrea Rossi

3.1. Ultrasound

3.1.1. Diaphragm thickness

3.1.2. Diaphragm thickening fraction and ratio

3.1.3. Diaphragm excursion

3.2. Optoelectronic plethysmography

3.3. Other investigations

Section 4. Respiratory muscle structure, perfusion and metabolism

Esther Barreiro, Joachim Gea, J. Alberto Neder, Roberto A. Rabinovich, loannis Vogiatzis

4.1. Near-infrared spectroscopy

4.2. Oxygen cost of breathing

4.3. Biopsy (specificities for respiratory muscles)

4.4. Typology

4.5. Mitochondrial function

4.6. Oxidative stress

4.7. Inflammation

Conclusion

References

Affiliations: 'Sorbonne Université, INSERM, UMRS1158 Neurophysiologie respiratoire expérimentale et clinique, Paris, France. ${ }^{2}$ AP-HP, Groupe Hospitalier Pitié-Salpêtrière Charles Foix, Service des Explorations Fonctionnelles de la Respiration, de l'Exercice et de la Dyspnée du Département R3S, Paris, France. ${ }^{3}$ Pulmonary Division, Heart Institute (InCor), University of São Paulo Medical School, São Paulo, Brazil. "SírioLibanês Teaching and Research Institute, São Paulo, Brazil. ${ }^{5}$ Dipartimento di Elettronica, Informazione e Bioingegneria, Politecnico di Milano, Milan, Italy. ${ }^{6}$ Institute for Exercise and Environmental Medicine, Texas Health Presbyterian Hospital Dallas and UT Southwestern Medical Center, Dallas, TX, USA. ${ }^{7}$ Pulmonology Department-Muscle and Respiratory System Research Unit (URMAR), CEXS, IMIM-Hospital del Mar, UPF, CIBERES, Barcelona, Spain. ${ }^{8}$ AP-HP, Groupe Hospitalier Pitié-Salpêtrière Charles Foix, Service de Pneumologie, Médecine Intensive et Réanimation du Département R3S, Paris, France. ${ }^{9}$ Département de Médecine, Service de Pneumologie, Centre Hospitalier de l'Université de Montréal (CHUM), Montréal, QC Canada. ${ }^{10}$ Centre de Recherche du Centre Hospitalier de l'Université de Montréal (CRCHUM) - Carrefour de l'Innovation et de l'Évaluation en Santé, Montréal, QC, Canada. ${ }^{11} \mathrm{AP}-\mathrm{HP}$, Hopital Necker, unité de ventilation noninvasive et du sommeil de l'enfant et université Paris Descartes, Paris, France. ${ }^{12}$ Servei de Pneumologia, Hospital del Mar DCEXS, Universitat Pompeu Fabra, CIBERES (ISCiii), BRN, Barcelona, Spain. ${ }^{13}$ Dept of Physical Therapy, University of British Columbia, Vancouver, BC, Canada. ${ }^{14}$ Centre for Heart Lung Innovation, Providence Health Care Research Institute, University of British Columbia, Vancouver, BC, Canada. 


\section{Introduction}

Assessing respiratory mechanics and respiratory muscle structure and function is an essential component of both clinical practice and research. It is especially useful in patients with respiratory symptoms and neuromuscular diseases (NMDs), contributing to diagnosis, patient phenotyping, assessment of treatment efficiency and patient follow-up. The American Thoracic Society (ATS) and the European Respiratory Society (ERS) published a statement on respiratory muscle testing in 2002, reviewing the rationale and technical characteristics of the main methods available [1]. Nearly two decades later, given the large amount of novel research in the field, the chairs of the present task force felt a need to summarise the latest knowledge on respiratory mechanics and muscle assessment both for clinicians and researchers. Since 2002, key advances have been made in the field of mechanics of breathing, respiratory muscle neurophysiology, and respiratory muscle imaging in health and disease, including in paediatrics and critically ill patients in the intensive care unit (ICU). A specific focus of the task force has been the assessment of respirator muscles and mechanics during exercise, a situation stressing the respiratory system and thus allowing the evaluation of respiratory muscle response to increased ventilatory demand.

\section{Methods}

The task force was formed in June 2016, composed of experts from the ERS Clinical Respiratory Physiology, Exercise and Functional Imaging Group (04.01), the ERS Rehabilitation and Chronic Care Group (01.02), the Physiotherapists Group (09.02), and representatives from the European Lung Foundation and the ERS Science Council. The task force received support from ERS methodologists throughout the project. Three meetings of the task force were held; two during the annual congress of the ERS (September 2016 and 2017) and one in Lausanne in March 2017. All task force members signed conflict of interest disclosures at the beginning of the project and updated them at project finalisation or when any new relevant conflict of interest appeared. Conflicts of interest were managed according to ERS rules.

Studies that reported the evaluation of respiratory muscles (inspiratory and expiratory) and upper airway muscles at rest or during exercise in adults and children with cardiorespiratory diseases were reviewed, without restrictions on study design. MEDLINE and Cochrane Library records from 1970 to 2017 were searched. Selected references considered to be of particular relevance were included up to June 2018. Reference lists of all primary studies and review articles were examined for additional citations. Only studies written in English, or for which an English translation was available, were consulted. Studies were included that refer (singly or in combination) to reported validity (i.e. the extent to which a test or variable is related to the function of a physiological system or to patient-meaningful variables, such as symptoms or exercise), precision or reproducibility, prognostic information (i.e. relationship with the natural history of the disease), discrimination (i.e. whether a variable can differentiate the severity of the disease as conventionally measured), clinical meaningful difference (i.e. the minimal difference in a tested variable that is considered to be functionally worthwhile or clinically important), or test response to interventions. Studies that did not meet the inclusion criteria based on title or abstract were excluded.

\footnotetext{
${ }^{15}$ Neuroscience Research Australia and University of New South Wales, Sydney, Australia. ${ }^{16}$ Dept of Internal Medicine II, Pneumology, Cardiology, Intensive Care Medicine, Academic Teaching Hospital Konstanz, Konstanz, Germany. ${ }^{17}$ Loyola University of Chicago Stritch School of Medicine, Maywood, IL, USA. ${ }^{18}$ Hines Veterans Affairs Hospital, Hines, IL, USA. ${ }^{19}$ Dept of Rehabilitation Sciences, Research Group for Cardiovascular and Respiratory Rehabilitation, KU Leuven - University of Leuven, Leuven, Belgium. ${ }^{20}$ Respiratory Rehabilitation and Respiratory Division, University Hospital Leuven, Leuven, Belgium. ${ }^{21}$ State Key Laboratory of Respiratory Disease, the First Affiliated Hospital of Guangzhou Medical University, Guangzhou, China. ${ }^{22}$ Laboratory of Clinical Exercise Physiology (LACEP), Division of Respiratory and Critical Care Medicine, Dept of Medicine, Queen's University and Kingston General Hospital, Kingston, ON, Canada. ${ }^{23}$ Respiratory Investigation Unit (RIU), Division of Respiratory and Critical Care Medicine, Dept of Medicine, Queen's University and Kingston General Hospital, Kingston, ON, Canada. ${ }^{24}$ Dept of Respiratory Medicine, Royal Brompton Hospital, London, UK. ${ }^{25}$ ELEGI Colt Laboratory, Centre for Inflammation Research, The Queen's Medical Research Institute, University of Edinburgh, Edinburgh, UK. ${ }^{26}$ Respiratory Medicine Dept, Royal Infirmary of Edinburgh, Edinburgh, UK. ${ }^{27}$ Pulmonary Unit, General Hospital, University of Verona, Verona, Italy. ${ }^{28}$ Centre de recherche Institut Universitaire de Cardiologie et de Pneumologie de Québec, Université Laval, Québec, QC, Canada. ${ }^{29}$ Exercise Physiology Lab, Institute of Human Movement Sciences and Sport, ETH Zurich; Zurich Center for Integrative Human Physiology (ZIHP), University of Zurich, Zurich, Switzerland. ${ }^{30}$ Columbia, St. Paul's Hospital, Vancouver, BC, Canada. ${ }^{31}$ National and Kapodistrian University of Athens, Faculty of Physical Education and Sports Sciences, Athens, Greece. ${ }^{32}$ Northumbria University Newcastle, Dept of Sport, Exercise and Rehabilitation, Newcastle, UK. ${ }^{33}$ Hypoxia Physiopathology laboratory (HP2), INSERM U1042, Grenoble Alpes University, Grenoble, France. ${ }^{34} \mathrm{P}$. Laveneziana and S. Verges are the project co-chairs.
}

Correspondence: Pierantonio Laveneziana, Service d'Explorations Fonctionnelles de la Respiration, de l'Exercice et de la Dyspnée, Département "R3S" (Respiration, Réanimation, Réhabilitation, Sommeil), Pôle PRAGUES, Hôpital Universitaire Pitié-Salpêtrière, Assistance Publique-Hôpitaux de Paris (AP-HP), 47-83 Boulevard de l'Hôpital, 75013, Paris, France. E-mail: pierantonio.lavenezianađaphp.fr 
Studies that met the inclusion criteria were retrieved in full text to determine whether they were suitable for inclusion. For each section, the articles selected by the primary task force author had to be approved by a second author with expertise in the field. Disagreements, if any arose, were resolved by consensus. The reader is advised and encouraged throughout the text to refer to the 2002 statement for the scientific basis and classical methodological approach of respiratory muscle function.

Of note, this statement contains additional information on respiratory muscle evaluation in two particular settings, of paediatrics and the ICU; due to manuscript constraints, these two settings are confined quasi-exclusively to the supplementary material, along with more technical and methodological details concerning each section of the article.

\section{Section 1. Respiratory muscle function}

1.1. Airway opening, oesophageal and gastric pressures: technical considerations

1.1.1. Pressure measurement

Respiratory muscles have two distinct functions: force development (pressure changes) and shortening (lung volume changes). Several key points must be considered [1]:

1) Pressures reflect barometric pressure difference.

2) In unaltered physiology/anatomy, specific pressures represent entire corresponding spaces. Gravity/ shear-stress affects pressure readings [2]. Figure 1 indicates pressure recording sites.

3) Pressure differences are assessed across corresponding structures. Table 1 lists thoracic pressure readings.

4) Pressure differences between two points reflect difference across at least two (group of) structures (e.g. chest wall/pleural cavity).

5) Pressure measurement reflects global muscle "output" (rather than contractile property per se).

6) Assessment occurs via voluntary manoeuvres or via evoked contractions (see below).

\subsubsection{Pressure assessment devices}

\subsubsection{Pressure transducers}

Frequency response flat up to $10-15 \mathrm{~Hz}$ assesses dynamic/static pressures [1]. Transducers should be calibrated in specific settings, since attached systems (e.g. catheters) alter frequency responses [3]. One should ensure identical frequency responses on both sides (differential transducers) [1]. Digital calibration is acceptable; however, a check via water manometer should be done regularly [1]. Pressure range should be $\pm 300 \mathrm{cmH}_{2} \mathrm{O}$ and resolution $\leqslant 0.5 \mathrm{cmH}_{2} \mathrm{O}[1]$.

FIGURE 1 Pressure recording sites. Abw: abdominal wall; aw: airway; Di: diaphragm; Eq: equipment; Lt: lung tissue; $P$ ab: abdominal pressure; Palv: alveolar pressure; $P$ ao: pressure at airway opening; $P_{\text {bs: }}$ body surface pressure; $P_{\mathrm{pl}}$ pleural pressure; rc: ribcage. Reproduced with permission of the publisher [1].

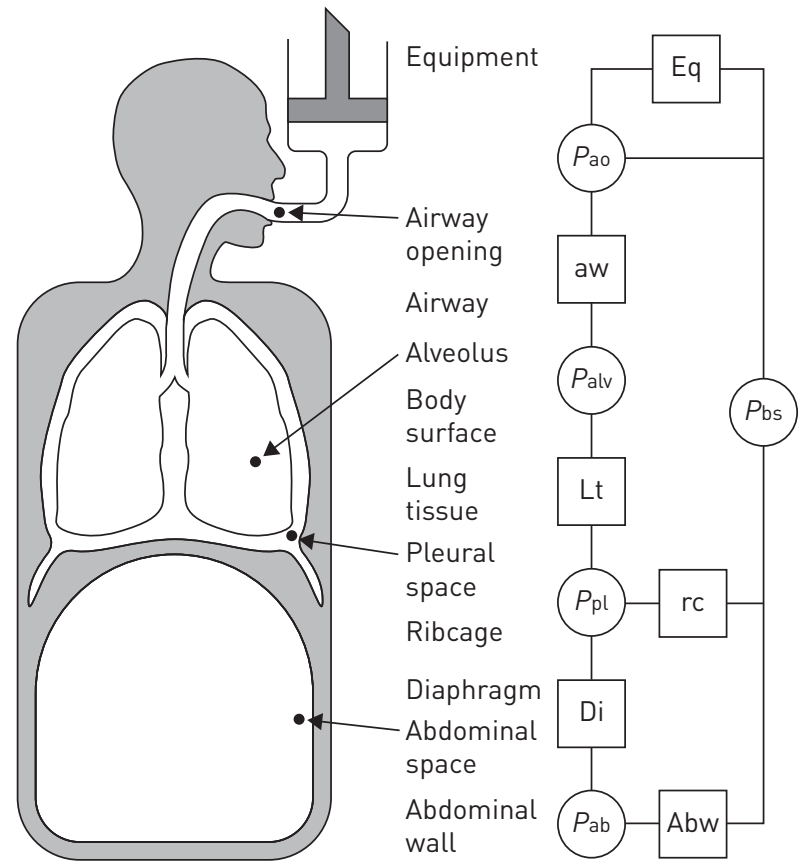




\section{TABLE 1 Thoracic pressure readings}

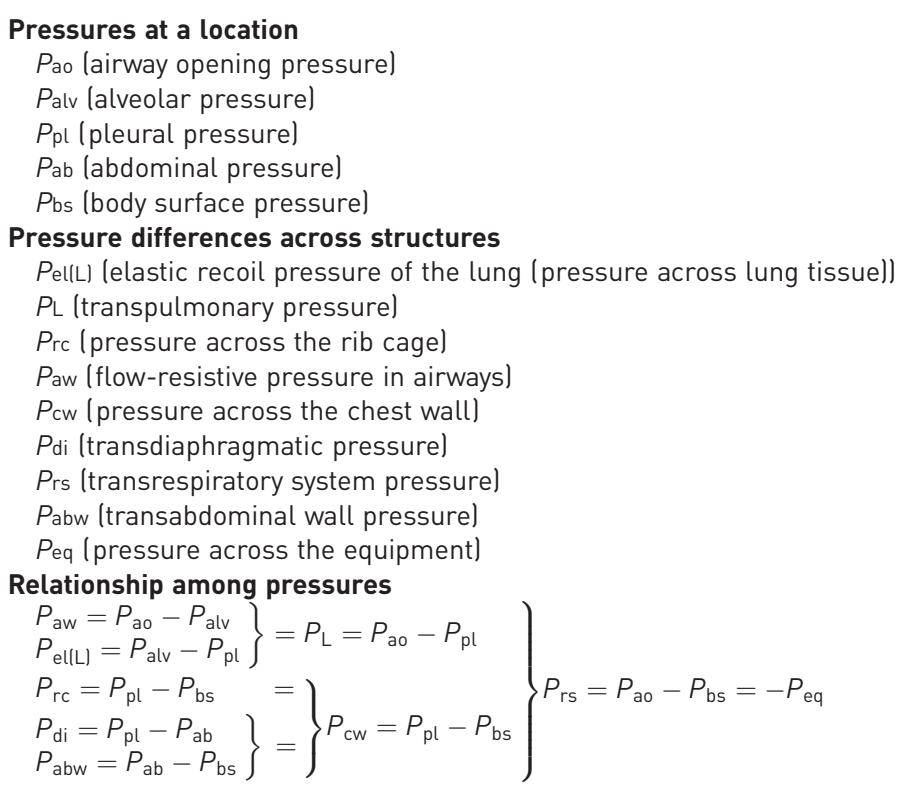

\subsubsection{Probes for invasive pressure assessment}

Air-filled balloon catheters are used to record oesophageal (Poes, $\sim$ pleural pressure) and gastric pressure ( $P$ ga, $\sim$ abdominal pressure) [4]. Specific characteristics need to be considered and standardised preparation is required [1,5]. Certain catheters additionally allow diaphragmatic electromyography (EMG) [1].

Repeated checking of air filling volumes and entire system volume displacement coefficient guarantees adequate balloon inflation $[1,5]$.

Appropriate system frequency responses (e.g. catheter diameter) are crucial for dynamic manoeuvres with high pressure changing rates (e.g. sniffs/twitches) [1]. Important characteristics include reasonable stiffness and several spirally arranged catheter holes at balloon portion, to avoid dampened signals $[1,5]$.

Liquid-filled catheters and catheter-mounted microtransducers have drawbacks (e.g. damped pressure signal in oesophagus/stomach or wide limits of agreement) and are not used in this setting $[1,6]$.

\subsubsection{Devices for measurement of airway opening pressure}

Airway opening pressure $(P a)$ is usually sampled from side taps ("lateral pressure") located in the mouthpiece/tracheal tube/facemask/nostril plug [1,7]. Nasal pressure reflects airway pressure only during undisturbed communication between nostrils/mouth with nasal flows [1]. The device to which the side tap is connected must have a cross-sectional area large enough to minimise the Bernoulli effect [8].

For $P$ ao to estimate alveolar pressure during dynamic respiratory efforts against an occluded airway, alveolaroral pressure transmission must be fast [1]. The transmission time constant depends on airway resistance and compliance of extrathoracic airways (i.e. mouth/cheeks/equipment) [1]. This is especially important when airway resistance increases (e.g. asthma, chronic obstructive pulmonary disease (COPD)) [1].

\subsection{Voluntary tests of respiratory muscle strength}

\subsubsection{Maximal static inspiratory and expiratory mouth pressure}

Measurements of maximum static inspiratory $(P \operatorname{Imax})$ or expiratory $(P$ Emax $)$ pressures at the mouth allow a simple assessment of global respiratory muscle strength in a clinical setting [1]. Tests are volitional and require full subject cooperation. PImax is usually measured at residual volume and PEmax at total lung capacity (TLC) to record the maximum value of three manoeuvres that vary by less than $10 \%$ (more details can be found in the supplementary material). Measuring PImax at functional residual capacity (FRC) has the advantage of representing the maximal static inspiratory pressure measured at the lung volume at which patients breathe tidally; however, it is greatly influenced by the level of lung hyperinflation or the severity of restriction, so careful attention should be paid under these conditions. 
PImax is strongly related to exertional dyspnoea (figure S4) [9]. The test might also serve as a screening instrument to identify patients with respiratory muscle weakness (figure 2, and supplementary material) [10]. Results should not be interpreted in isolation but together with the overall clinical picture (pathology, symptoms, and load/capacity balance during daily activities). The test is responsive to evaluate changes within subjects. Characteristics of studies that provide reference values for PImax and PEmax measurements are summarised in the supplementary tables S2-S8 [11]. Measurements of mouth pressures are also used in cooperative children older than 6-8 years of age (table S14), and to evaluate muscle strength in the ICU (supplementary material).

\subsubsection{Maximal sniff nasal inspiratory pressure}

During measurement of maximal sniff nasal inspiratory pressure (SNIP), inspiratory pressure is recorded by a pressure transducer connected to a catheter placed in the nostril [12]. The test is performed at FRC. The subject is instructed to sniff quickly and deeply. SNIP has been validated in healthy individuals [12] and patients with COPD [13], and is also very useful for children $>2$ years of age [14]. Precision is good in healthy subjects without severe nasal congestion. Even in COPD there is good repeatability [13]. More information including normative values is presented in supplementary table S9.

\subsubsection{Peak cough flow}

Peak cough flow (PCF) estimates the effectiveness of mucus clearance and expiratory muscle function in neuromuscular disorders $[15,16]$. The measurement is performed with subjects seated. An oronasal mask/ mouthpiece is connected to a pneumotachograph or peak flow meter. Subjects are instructed to perform a maximal cough after complete inhalation [17]. They should perform 3-6 manoeuvres ( $<5 \%$ variability) and the maximum PCF (L·min ${ }^{-1}$ ) should be reported [17]. In NMDs, (manually) assisted PCF might be appropriate [18]. Hand-held peak flow meter devices might overestimate PCF if spirometer recordings of PCF are $<270 \mathrm{~L} \cdot \mathrm{min}^{-1}[17]$.

PCF informs the need to start manual/mechanical exsufflator/insufflator therapy because PCF $<270 \mathrm{~L} \cdot \mathrm{min}^{-1}$ is associated with higher likelihood of pulmonary complications in neuromuscular disorders [17]. Healthy (children) adults achieve PCF measurements of approximately (150) 470-600 L·min ${ }^{-1}$; PCF

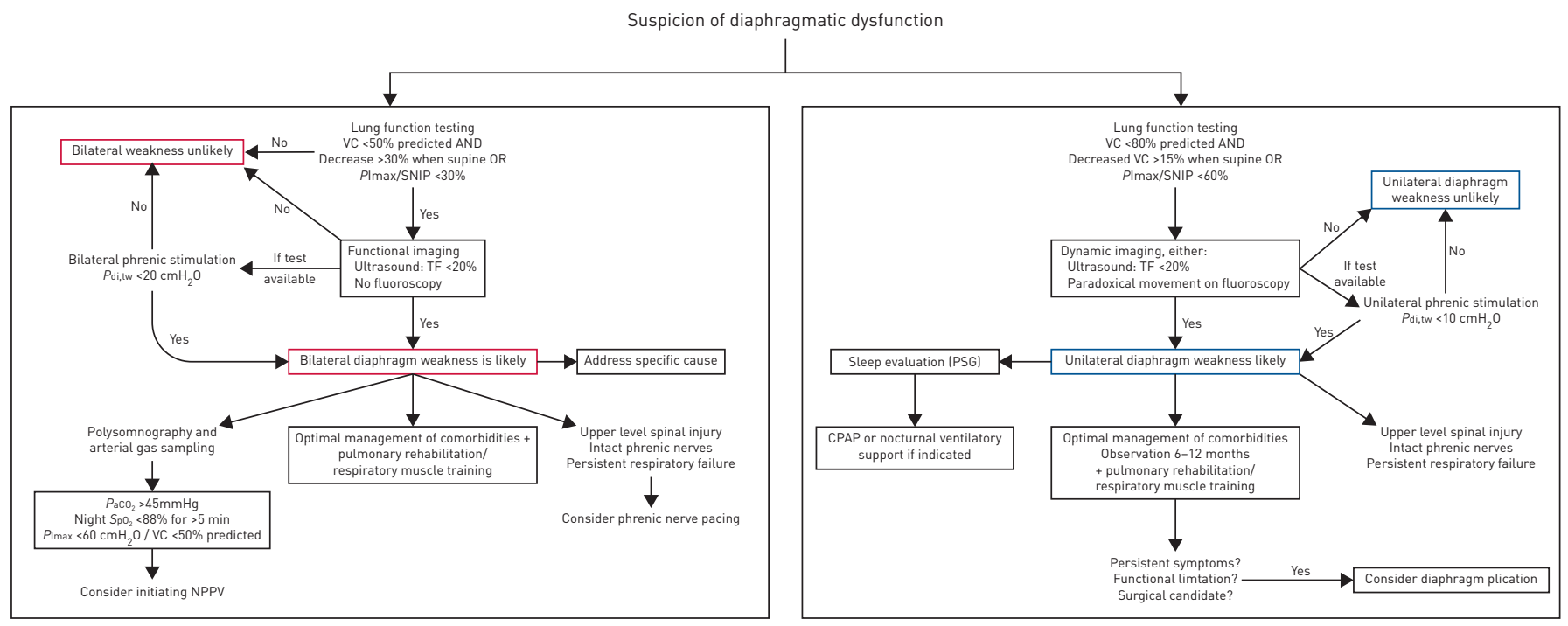

FIGURE 2 Expert opinion on the suspicion of diaphragmatic dysfunction. The figure describes the current practice of how the members of the task force suspect and treat respiratory muscle dysfunction (especially for unilateral and bilateral diaphragm weakness), outside of the intensive care setting (this is, however, not intended as a recommendation for clinical practice). In the absence of clearly defined lower limits of normal, it has long been accepted that a PImax or sniff- $P_{\text {di }}$ or $P$ dimax $\geqslant 80 \mathrm{~cm} \mathrm{H}_{2} \mathrm{O}$ in men and $\geqslant 70 \mathrm{cmH}_{2} \mathrm{O}$ in women, and/or $\mathrm{SNIP} \geqslant 70 \mathrm{cmH} \mathrm{H}_{2} \mathrm{O}$ in men and $\geqslant 60 \mathrm{cmH}_{2} \mathrm{O}$ in women are generally thought to exclude clinically significant inspiratory muscle weakness [1], and unilateral and bilateral diaphragm paralysis can be expected to decrease PImax or SNIP in the ranges of $60 \%$ [41] and $<30 \%$ [42] of the predicted values, respectively. However, these values may be greatly impacted by the presence of underlying obstructive or restrictive lung disease $[40]$. A $P$ di,tw $>10 \mathrm{cmH} \mathrm{H}_{2} \mathrm{O}$ with unilateral phrenic nerve stimulation or $>20 \mathrm{cmH}_{2} \mathrm{O}$ with bilateral phrenic nerve stimulation also rules out clinically significant weakness [1]. Please refer to the text for more details. SNIP: sniff nasal inspiratory pressure; VC: vital capacity; PImax: maximal inspiratory pressure; TF: thickening fraction of the diaphragm; PSG: polysomnography; CPAP: continuous positive airway pressure; $P_{\text {di: }}$ transdiaphragmatic pressure; $P_{\text {di,tw: }}$ twitch transdiaphragmatic pressure; NPPV: noninvasive positive pressure ventilation; $P_{\mathrm{aCO}}$ : arterial partial pressure of carbon dioxide; $\mathrm{SpO}_{2}$ : peripheral oxygen saturation. 
$<160 \mathrm{~L} \cdot \mathrm{min}^{-1}$ is associated with higher likelihood of extubation/weaning failure in neuromuscular disorders (more details can be found in the supplementary material) $[17,19]$.

\subsection{Voluntary manoeuvres with oesophageal and gastric pressures}

Measurements of $P_{\text {oes}}, P_{\text {ga }}$ and transdiaphragmatic pressure $\left(P_{\mathrm{di}}=P_{\mathrm{ga}}-P_{\mathrm{oes}}\right)$ while sniffing and coughing are useful when noninvasive measures of in- and expiratory muscle function (e.g. SNIP or PCF) provide equivocal information. Assessments during sniff are particularly useful when SNIP yields suspiciously low values, e.g. in patients with upper airway obstruction (hypertrophy of the adenoids, rhinitis, polyps) or lower airway obstruction. Assessments during cough are needed to assess the expiratory muscles when glottis function is compromised, for example in patients with bulbar amyotrophic lateral sclerosis (ALS). These measurements may also be used to refine clinical diagnosis $[20,21]$. Maximal muscle relaxation rate (MRR) can provide additional information on respiratory muscle function [22, 23] but its clinical application is limited. Measurements of $P_{\text {oes }}$ and Pga during voluntary manoeuvres can also be obtained in the ICU and in children (supplementary material).

In adults, the average within-subject, between-occasion coefficient of variation $(\mathrm{CV})$ is $11 \%$ for sniff- $P_{\mathrm{di}}$ [24] and $6.9 \%$ for cough-Pga (table 2) [21]. No such values are available for children. For sniff-MRR, within-subject and between-occasion CVs range from 6 to $26 \%$ [25].

Reference values are given in table 2 where available.

In many diseases, pressures produced during sniff and cough are less than normal, both in adult patients (e.g. heart failure [26], stroke [27], COPD [25], pulmonary fibrosis [25], cystic fibrosis [28] and NMDs $[20,21,29])$ and in children with NMDs [30, 31]. In a cohort of patients with mixed diagnoses [20], adding SNIP to PImax reduced the false-positive diagnosis of inspiratory muscle weakness by $20 \%$ (with sniff- $P$ di not adding more diagnosis accuracy). Adding cough- $P$ ga to $P$ Emax decreased false-positive diagnosis of expiratory muscle weakness by $30 \%$ [20].

The use of sniff- $P$ di and cough- $P$ ga has not been widely explored for prognosis. In ALS patients, sniff- $P_{\mathrm{di}}$ correlated with SNIP [32] and SNIP $<40 \mathrm{cmH}_{2} \mathrm{O}$ was associated with desaturation during sleep; hazard ratio for death was 9.1. Sniff- $P$ di, sniff- $P_{\text {oes }}$ and twitch $P_{\mathrm{di}}\left(P_{\mathrm{di}}, \mathrm{tw}\right.$, see below) were significant predictors of ventilation-free survival in ALS patients [33], while PEmax and transdiaphragmatic pressure elicited by phrenic nerve stimulation ( $P$ di,tw) were predictors of absolute survival.

After lung volume reduction surgery [34], sniff-Pdi, SNIP and PImax increased significantly, while 8 weeks of rehabilitation did not add any further improvement [34].

In COPD, after exhaustive treadmill walking, sniff-Poes did not change significantly; sniff-Poes-MRR decreased by $42 \%$, and recovered within 5 min of rest [35].

\subsection{Respiratory muscle-related mechanics of breathing \\ 1.4.1. Lung function testing}

Pulmonary function tests, especially measurements of upright and supine vital capacity (VC), which depends on activation of both inspiratory and expiratory muscles [36], are noninvasive and readily available measurements contributing to the evaluation of respiratory muscle function, especially the diaphragm [36-39]. Unilateral diaphragm weakness is usually associated with a modest decrease in VC, to approximately $75 \%$ of predicted $[40,41]$, with a further $10-20 \%$ decrease in the supine position $(15 \%$ which represents twice the $\mathrm{CV}$ of the measure could be considered the lower limit of normal) (figure 2) [41], while FRC and TLC are usually preserved [40,41]. In severe bilateral diaphragm weakness, VC is usually $50 \%$ of predicted and can further decrease by $30 \%$ or more when supine [42]. A normal supine VC makes the presence of clinically significant diaphragmatic weakness unlikely.

TLC can also be reduced ( $70-79 \%$ of the predicted value with mild weakness, up to $30-50 \%$ of the predicted value in moderate-to-severe weakness), while residual volume can be elevated [43]. Of note, in patients with diaphragm weakness, the magnitude of fall in $\mathrm{VC}$ in the supine position correlates with the reduction in sniff- $P$ di $[43]$.

In many NMDs [44-50], such as ALS, a significant reduction of VC at diagnosis, as well as its rate of decline over time, are recognised as criteria for initiating noninvasive ventilation [51,52]. Reduction in VC is also predictive of sleep disordered breathing, respiratory failure, worse prognosis and response to treatment, to a lesser extent, with good sensitivity (80-95\%) but quite variable specificity (50-90\%) [53].

\subsubsection{Indices of respiratory muscle effort}

The pressure output of the respiratory muscles can be assessed by calculating 1) the work of breathing (WOB), 2) the pressure-time product (PTP) of either the oesophageal pressure (PTPoes; reflecting 


\begin{tabular}{|c|c|c|c|c|c|c|}
\hline Tests & $\begin{array}{l}\text { Main } \\
\text { variables }\end{array}$ & $\begin{array}{l}\text { Reference values and } \\
\text { discriminative values }\end{array}$ & Repeatability/reliability/validity & Cautions & $\begin{array}{l}\text { Setting (expert centres, } \\
\text { general clinical use, } \\
\text { research, etc.) }\end{array}$ & Remarks \\
\hline \multirow[t]{4}{*}{$\begin{array}{l}\text { Voluntary } \\
\text { manoeuvres } \\
\text { with mouth } \\
\text { pressure }\end{array}$} & $P \operatorname{lmax}$ & Yes (tables S2-S4) & $\begin{array}{l}\text { Sufficiently repeatable and reliable } \\
\text { measurements in untrained subjects } \\
(<10 \% \text { variability between efforts) can } \\
\text { usually be obtained within } 5 \text { efforts } \\
\text { [297]. Peak values are typically } \\
\text { reached after } 9 \text { attempts [298]. }\end{array}$ & $\begin{array}{l}\text { Standardisation of lung volumes, } \\
\text { mouthpiece and recorded pressure } \\
\text { (peak versus plateau) required. }\end{array}$ & $\begin{array}{l}\text { SNIP and mouth } \\
\text { pressures can be used } \\
\text { in clinical practice } \\
\text { after thorough training } \\
\text { of the procedures. }\end{array}$ & $\begin{array}{l}\text { Always to be interpreted in } \\
\text { clinical context of symptoms } \\
\text { and diagnosis. }\end{array}$ \\
\hline & $P_{\text {Emax }}$ & Yes (tables S5 and S6) & $\begin{array}{l}\text { Reliable peak values usually achieved } \\
\text { after } 5-6 \text { efforts. Within subject } \\
\text { between occasion coefficient of } \\
\text { variation around } 10 \% \text { [21]. }\end{array}$ & $\begin{array}{l}\text { Standardisation of lung volumes, } \\
\text { mouthpiece and recorded pressure } \\
\text { (peak versus plateau) required. }\end{array}$ & & $\begin{array}{l}\text { Always to be interpreted in } \\
\text { clinical context of symptoms } \\
\text { and diagnosis. }\end{array}$ \\
\hline & SNIP & Yes (table S9) & $\begin{array}{l}\text { Yes. Possibly fewer efforts needed for } \\
\text { acceptably reliable measurements in } \\
\text { comparison to PImax in untrained } \\
\text { subjects }[12,13,20,299,300] .\end{array}$ & $\begin{array}{l}\text { Cautions in subjects with severe nasal } \\
\text { congestion. } \\
\text { Although SNIP and PImax has a good } \\
\text { correlation, the agreement between } \\
\text { these two methods is variable. Thus, } \\
\text { they are complementary and not } \\
\text { interchangeable in the evaluation of } \\
\text { inspiratory weakness }\end{array}$ & $\begin{array}{l}\text { SNIP in association with } \\
\text { PImax reduces the } \\
\text { false-positive diagnosis } \\
\text { of inspiratory } \\
\text { weakness by nearly } \\
20 \% \text { [5]. }\end{array}$ & $\begin{array}{l}\text { Should be used as a } \\
\text { complementary variable (i.e. } \\
\text { in addition to a first screening } \\
\text { with mouth pressures) to } \\
\text { investigate inspiratory } \\
\text { weakness. } \\
\text { Always use the reference } \\
\text { values of your population } \\
\text { when available. }\end{array}$ \\
\hline & PCF & $\begin{array}{l}\text { Healthy subjects: } \\
\text { 468-588 L-min }{ }^{-1}[301] \\
\text { Increased extubation/weaning } \\
\text { failure }<160 \mathrm{~L} \cdot \mathrm{min}^{-1} \text { in } \\
\text { NMD patients [302] }\end{array}$ & No sufficient data available. & $\begin{array}{l}\text { At least } 3-6 \text { PCF with }<5 \% \text { variability need } \\
\text { to be assessed [17] }\end{array}$ & $\begin{array}{l}\text { Simple to assess. } \\
\text { Especially useful in } \\
\text { NMD patients. }\end{array}$ & $\begin{array}{l}\text { No direct link between "cut-off" } \\
\text { values and clinical } \\
\text { consequences (e.g. cough } \\
\text { assist). }\end{array}$ \\
\hline \multirow{2}{*}{$\begin{array}{l}\text { Voluntary } \\
\text { manoeuvres } \\
\text { with } \\
\text { oesophageal and } \\
\text { gastric } \\
\text { pressures }\end{array}$} & & & $\begin{array}{l}\text { Be careful with dose of local } \\
\text { anaesthesia. }\end{array}$ & & & \\
\hline & Sniff & $\begin{array}{l}\text { No normal values exist; } \\
\text { mean } \pm \text { sD (range) achieved } \\
\text { by healthy subjects: } \\
\text { Pdi (37 M): } 148 \pm 24 \\
(111-124,126-204) \mathrm{cmH}_{2} \mathrm{O} \\
{[303]} \\
P_{\text {di }}(27 \mathrm{~F}): 122 \pm 25 \text { (82-182) } \\
\mathrm{cmH}_{2} \mathrm{O}[303] \\
P_{\text {di }}(64): 136 \pm 37(82-204) \\
\mathrm{cmH}_{2} \mathrm{O}[303] \\
P_{\text {di }}(32): 134 \pm 24(86-195) \\
\mathrm{cmH}_{2} \mathrm{O}[24] \\
P_{\text {oes }}(37 \mathrm{M}): 105 \pm 26 \\
(52-150) \mathrm{cmH}_{2} \mathrm{O}[303] \\
P_{\text {oes }}(27 \mathrm{~F}): 92 \pm 22(52-140) \\
\mathrm{cmH}_{2} \mathrm{O}[303]\end{array}$ & CV- $P_{\text {di }}$ (healthy adults): $11 \%$ [24] & NA & Expert centre research & $\begin{array}{l}\text { SNIP/sniff- } P_{\text {oes }} \text { (children): } \\
\text { CF } 0.72 \pm 0.13 \text { [28] } \\
\text { NMD patients } 0.83 \pm 0.17 \text { [28] } \\
\text { Thoracic scoliosis } 0.86 \pm 0.10 \\
\text { [28] } \\
\text { 3-year ventilator-free survival in } \\
\text { ALS patients: sniff- } P_{\text {di }} \text { cut-off } \\
108.5 \mathrm{cmH}_{2} \mathrm{O} \text { (sensitivity } 0.85 \text {, } \\
\text { specificity } 0.98 \text { ) [33] }\end{array}$ \\
\hline
\end{tabular}




\section{TABLE 2 Continued}

Tests Main

Reference values and

Repeatability/reliability/validity

Cautions

Setting lexpert centres, Remarks

general clinical use,

research, etc.)

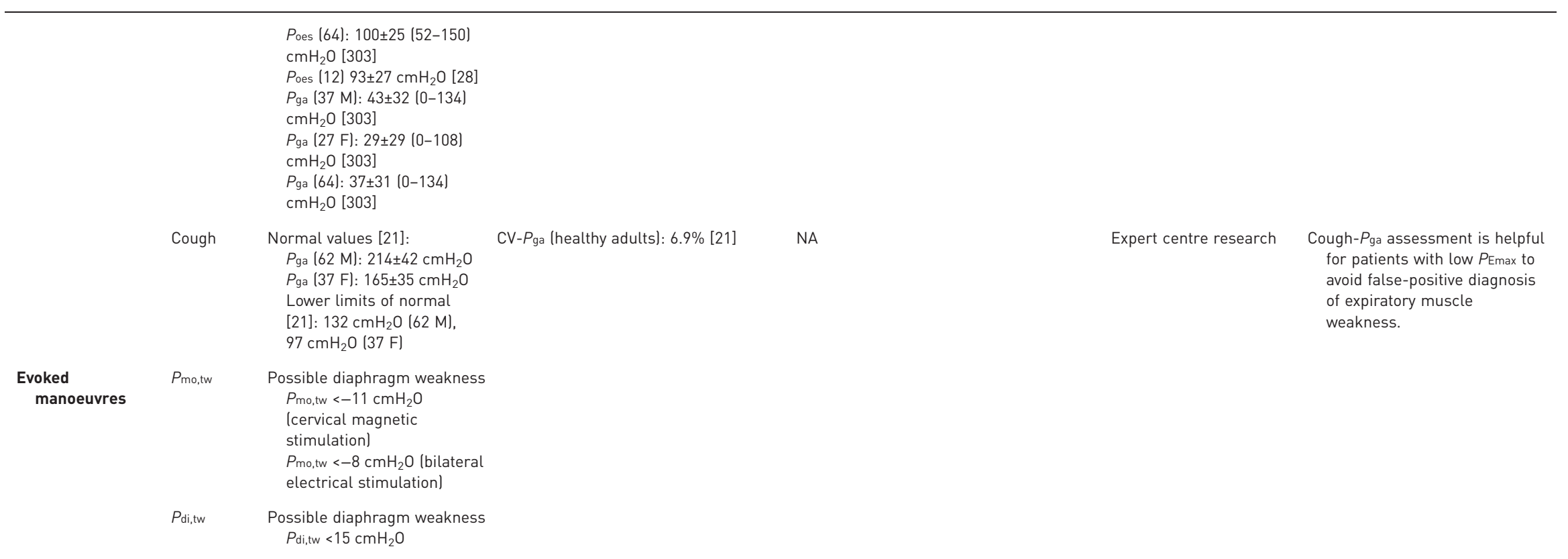

PImax: maximal inspiratory pressure; PEmax: maximal expiratory pressure; SNIP: maximal sniff nasal inspiratory pressure; PCF: peak cough flow; NMD: neuromuscular disease; Poes: oesophageal pressure; Pga: gastric pressure; Pdi: transdiaphragmatic pressure; Pmo: mouth pressure; Pdi,tw: twitch transdiaphragmatic pressure; Pmo,tw: twitch mouth pressure; ALS: amyotrophic lateral sclerosis; CF: cystic fibrosis; M: male; F: female; CV: coefficient of variation; NA: not applicable. 
the effort done by all of the respiratory muscles), the transdiaphragmatic pressure (PTPdi; reflecting mostly the effort done by the diaphragm) [54], 3) the tension-time index (TTI=PI/PImax $\times t \mathrm{t} /$ tot $)$ or 4$)$ the $\mathrm{P}_{\text {oes }}$ swing. Details on how these indices are calculated, their physiological underpinning, advantages and disadvantages are described in the supplementary material. PTP analyses have been used as an alternative to WOB to quantify respiratory muscle effort in both healthy subjects $[55,56]$ and patients with COPD [57-59]. PTP is more closely related to respiratory muscle oxygen consumption than WOB [60]. The average value for PTP in healthy subjects is around $100 \mathrm{cmH}_{2} \mathrm{O} \cdot \mathrm{s} \cdot \mathrm{min}^{-1}$ while in acute respiratory failure, the average PTP has been reported to be about four-fold greater [61]. During trials of weaning from mechanical ventilation, PTPoes can predict weaning failure [61]. PTP is greater in COPD patients during exercise compared with age- and sex-matched healthy controls [62].

In the clinical setting, inspiratory effort can be simply monitored by measuring tidal swings in Poes (Poes,tid) (figure 3) [63]. Poes,tid can serve as an index of global respiratory muscle effort during exercise in patients with chronic respiratory diseases [64]. Poes,tid can identify differences in disease severity between patients with COPD (i.e. by Global Initiative for Chronic Obstructive Lung Disease stages) [65] and it is sensitive to changes over time and to interventions [65]. Increases in Poes,tid relative to stable tidal volume responses are related to the perception of dyspnoea during exercise $[64,66]$. Poes,tid has been successfully applied as a bedside monitoring tool in sleep studies [67], and during weaning trials [68]. Poes,tid (in analogy with the PTPoes) showed larger changes over the course of a failed weaning trial than breathing pattern parameters (rapid shallow breathing index) [61, 68].

Reduction of resistive and elastic load by continuous positive airway pressure or inspiratory pressure support can reduce inspiratory effort. During exercise, these reductions in inspiratory effort decrease exercise-associated dyspnoea and improve exercise tolerance in patients with COPD [57, 69]. Similar results can be obtained using helium hyperoxia and bronchodilators [70]. It is difficult to establish a minimal clinically important difference of indices of respiratory muscle effort, given the paucity and heterogeneity of the studies. Nonetheless, a clinically meaningful difference of $14-16 \%$ from baseline condition has been shown to correlate with a clinically meaningful reduction of exertional dyspnoea after pharmacological intervention such as bronchodilators for both PTP and Poes,tid [71-73]. Finally, exercises that promote slow and deep breathing have the potential to reduce the elastic component of WOB and thereby reduce inspiratory effort [74-76]. In addition, changes in inspiratory duty cycle (decreased $t \mathrm{t} / \mathrm{ttot}$ ) induced by these breathing techniques can further reduce PTP by reducing inspiratory time per minute [77]. Measurements of pressure during brief inspiratory occlusions (typically $0.1 \mathrm{~s}$ ) applied without warning before the individual recognises the occlusion and reacts (i.e. $P_{0.1}$ ) can be a useful index of respiratory centre motor output (supplementary material).

\subsection{Evoked manoeuvres}

Non-volitional evaluation of diaphragm (dys)function and fatigue (i.e. a reduction in the ability to produce force/pressure following contractile activity) can be performed by phrenic nerve stimulation; diaphragm

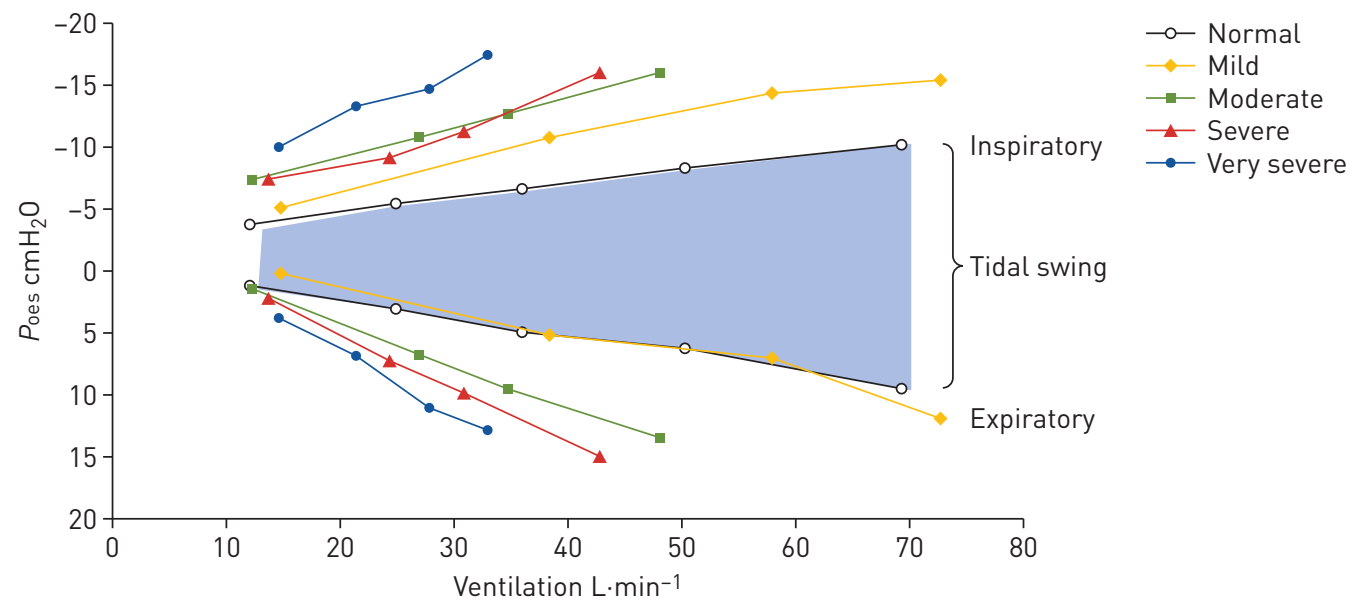

FIGURE 3 Tidal oesophageal pressure ( $P_{\text {oes}}$ ) swings are shown with varying severity of chronic obstructive pulmonary disease and in age-matched healthy control subjects. As disease severity worsens, the amplitude of inspiratory and expiratory $P_{\text {oes }}$ increases for a given ventilation during exercise. The shaded area

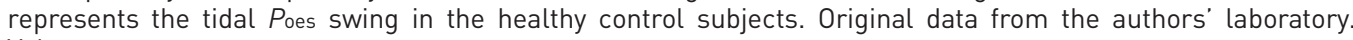
Values are means. 
contraction causes a sudden and short-lasting fall in $P_{\text {oes }}$ and a rise in $P_{\text {ga, }}$, the difference providing $P_{\text {di,tw. }}$ Abdominal muscles can be evaluated by stimulation of thoracic nerve roots with measurement of gastric pressure $\left(P_{\text {ga,tw }}\right)$.

Magnetic phrenic nerve stimulation has superseded electrical stimulation, except where patients have pacemakers or other implanted electronic devices where magnetic stimulation is contraindicated. Technical considerations during phrenic nerve stimulation include: 1) stimulation must be supramaximal, 2) potentiation resulting from prior contraction must be avoided or standardised, 3) lung volume must be standardised, and 4) different magnetic stimulation techniques (e.g. cervical, bilateral anterior) yield different results and should be used consistently. A noninvasive estimate of $P$ di,tw can be obtained by measuring pressure changes in the upper airway or the mouth $\left(P_{\mathrm{mo}, \mathrm{tw}}\right)$ [78] although oesophageal twitch pressure $\left(P_{\text {oes,tw) }}\right.$ and thus $P$ mo,tw are more influenced by lung volume than $P$ di,tw.

Resting values of $P$ ga,tw have a slightly higher variability (CV 9-10\%) than Pdi,tw (6\%).

Age- and sex-specific normal values for adults are lacking, but a cut-off for $P$ di,tw of $18 \mathrm{cmH}_{2} \mathrm{O}$ has been suggested for diagnosis of diaphragm weakness [20]. In healthy subjects, the mean between-occasion variability in $P$ di,tw is $20 \pm 11 \%$ and CV $11 \%$ [79]. The limit of agreement of the difference of $P$ di,tw recordings is $\pm 6 \mathrm{cmH}_{2} \mathrm{O}$ [79]. Variations in Pdi,tw with disease are shown in table 3.

Exhaustive exercise in healthy subjects can elicit a fall in Pditw (showing diaphragm fatigue), while in a variety of disease states exercise-induced diaphragm fatigue has been reported by some but not all investigators (please refer to supplementary material for more details). Of note, diaphragm fatigue is not necessarily related to exercise performance and development of fatigue may not predict clinical outcomes [80].

Normal $P$ di,tw values are available for neonates [81], infants [82] and children [83], in whom stimulation is acceptable with local anaesthesia. In critically ill patients, measurement of $P$ ao,tw and $P$ di,tw can be particularly useful and several large case series yielded $P$ ao,tw or $P$ di,tw values $[84,85]$ that are lower than those recorded in healthy individuals (please refer to supplementary material for further details).

\subsection{Respiratory muscle endurance testing}

Different approaches can be used to assess respiratory muscle endurance: 1) incremental load testing, 2) constant load testing and 3) time trials. Different tests were developed within these categories: 1) a stepwise load increase by increasing resistance/threshold load or minute ventilation, 2) sustaining a given resistance/threshold load or hyperpnoea level to task failure and 3) time trial, where a maximum ventilation (with/without additional resistance) must be achieved within a given duration. While resistive/ threshold loading tests mostly apply inspiratory loads [86], hyperpnoea tests load both inspiratory and expiratory muscles [87].

Since test performance is influenced by breathing pattern, breathing frequency and tidal volume should be controlled (feedback) and/or reported [88-90]. When testing pre/post-interventions, starting load/ ventilation and increments (if present) need to be identical.

TABLE 3 Summary of the main causes of perturbation in twitch transdiaphragmatic pressure $\left(P_{\mathrm{di}}, \mathrm{tw}\right)$

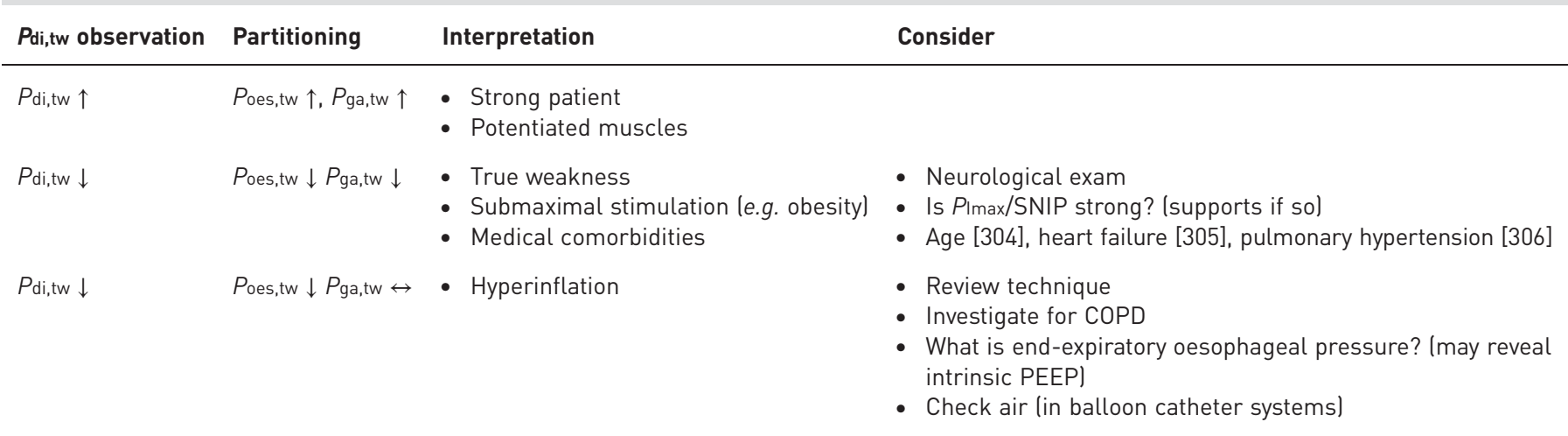

Poes,tw: oesophageal twitch pressure; Pga,tw: gastric twitch pressure; PImax: maximal inspiratory pressure; SNIP: sniff nasal inspiratory pressure; COPD: chronic obstructive pulmonary diseases; PEEP: positive end-expiratory pressure. 


\subsubsection{Maximal incremental load testing}

Resistive/threshold testing requires subjects to breathe against a resistive/threshold [1, 89] or tapered flow-resistive [86] load that is increased at regular intervals (minutes or number of breaths), e.g. by $10 \%$ of baseline PImax until task failure. Inspiratory muscle endurance can be defined as the pressure of the last completed step.

Hyperpnoea testing uses stepwise increasing minute ventilation (e.g. $+8 \%$ of maximal voluntary ventilation (MVV) every $3 \mathrm{~min}$ ) [1]. It needs special equipment to assure normocapnia and has been increasingly applied in recent years [90]. Ventilatory levels achieved in this test were found to be similar to levels reached in the traditional maximal sustainable ventilation test [91, 92]. Normal values have been established for healthy subjects [90].

\subsubsection{Constant load testing}

During resistive/threshold testing, subjects are instructed to breathe against a submaximal load $[86,88,89]$ until task failure. It has been proposed that the selected load should result in a time to task failure ( $t$ lim) of 5-10 min, such that post-intervention test durations can be limited to about 15-20 min without important ceiling effects [86, 89]. Main outcomes are tlim and/or total external work performed during the test [86]. The pattern of breathing during such a test is important and must be taken into account when analysing the data.

During hyperpnoea testing, subjects breathe at a constant ventilation (40-70\% MVV) to achieve task failure within $8-12 \mathrm{~min}$.

\subsubsection{Time trial}

The 10-15 s MVV manoeuvre is too short-lasting for assessment of respiratory muscle endurance. Different protocols exist for testing maximal sustainable ventilation, i.e. the ventilation that can be sustained for a given, extended period of time (e.g. 12-15 min). However, there is no consensus on which protocol to use for this kind of test [1].

The attraction of these different respiratory muscle endurance tests is that they provide a method for evaluating global respiratory muscle endurance in a single test session. The tests are noninvasive and relatively well-tolerated. Several studies showed large improvements in respiratory muscle endurance after respiratory muscle training by using these tests (supplementary material).

\section{Section 2. Respiratory muscle neurophysiology}

Respiratory muscle neurophysiological testing includes 1) EMG to measure the output of the respiratory motor neurons, 2) electroencephalography (EEG), which tests the involvement of motor and premotor areas, and 3) transcranial magnetic stimulation (TMS) which assesses the neural pathways to the respiratory muscles (figure 4 ).

\subsection{Electromyography}

EMG is the technique that quantifies the electrical activity of muscles and is used in research and clinical practice to assess respiratory muscle control at rest and during exercise, including estimation of respiratory motor output (as previously reviewed [93, 94]), neuromechanical coupling during loaded breathing [95] and the efficacy of muscle contraction when coupled with measurements of ventilation [96, 97]. Finally, EMG can also be used in the diagnosis of myopathic and neuropathic diseases [1]. A thorough review of the theoretical background and methodology of respiratory EMG recordings is available [1].

Respiratory EMG can be recorded with surface electrodes, an oesophageal electrode inserted via the nose, and intramuscular wire or needle electrodes. Appropriate selection of electrodes depends on the EMG technique (e.g. physiological recordings versus evoked responses), the target muscle, signal reliability and safety (table 4).

Respiratory EMG measurement is usually contaminated with ECG readings, which should be eliminated $[98,99]$ or excluded from EMG measures. Moreover, respiratory EMG recordings, especially with surface electrodes, are subject to electromagnetic interference $[1,94,100]$, contamination from adjacent muscles and changes in lung volume or posture $[1,101]$. Diaphragm EMG can be quantified with a multi-pair oesophageal electrode $[102,103]$, usually standardised to a maximal value (table 4 ). Given its noninvasive nature, surface parasternal intercostal EMG has been proposed as an alternative measure of respiratory motor output, respiratory load-capacity balance and, potentially, lung disease severity [104-107], but may not be useful during exercise testing [108]. The single motor unit technique can accurately assess respiratory motor output [93] and avoids many of the caveats related to contamination of EMG signals 
and normalisation. For evoked responses, normal values of phrenic nerve conduction time are available using either electrical or magnetic stimulation (table 4) $[1,94,109,110]$.

The reliability of these respiratory EMG techniques is reported in table 4.

Respiratory EMG has been used to assess respiratory muscle control in cardiorespiratory disease at rest (table S10) and during exercise (table S11). Briefly, diaphragm EMG is a surrogate of respiratory effort [102, 111-113], it can be used to distinguish between central and obstructive sleep apnoea events $[111,112,114]$, to assess exertional breathlessness during exercise $[64,97,115,116]$ and, when combined with $V \mathrm{~T}$ recordings, it can be used to assess upper airway resistance $[112,117]$. Given increased respiratory motor output to the respiratory muscles in COPD $[118,119]$ and the relationship between EMG and lung function, respiratory EMG has been taken as a marker for disease severity in stable COPD [103] and to predict COPD exacerbations [105], early hospital admission [107] and the effect of medical interventions [120-122].

In the ICU, recordings of the electrical activity of the crural diaphragm (EAdi) using a dedicated nasogastric tube with EMG electrodes has greatly facilitated bedside monitoring of diaphragm activity in both paediatric [123] and adult patients [124]. The EAdi signal can be used to trigger and determine the level of assistance during mechanical ventilation, i.e. "neutrally adjusted ventilatory assistance" [125]. The ratio of actual EAdi to maximum EAdi can be used to estimate the patient's effort to breathe [126]. EAdi is a promising tool for diaphragm activity monitoring, especially during the weaning phase [127].

\subsection{Electroencephalography}

Respiratory-related cortical networks are not normally activated during resting breathing [128], carbon dioxide stimulation [128], or the ventilatory response to exercise [129]. In contrast, these networks are engaged during voluntary respiratory manoeuvres (apnoea, sniffing or hyperventilation) [128, 130, 131]. They are also engaged when the respiratory system is used for non-respiratory purposes, such as speech [132]. Induction of respiratory neuroplasticity using repetitive TMS have suggested these networks exert a tonic excitatory influence on breathing during wakefulness [133]. The respiratory-related
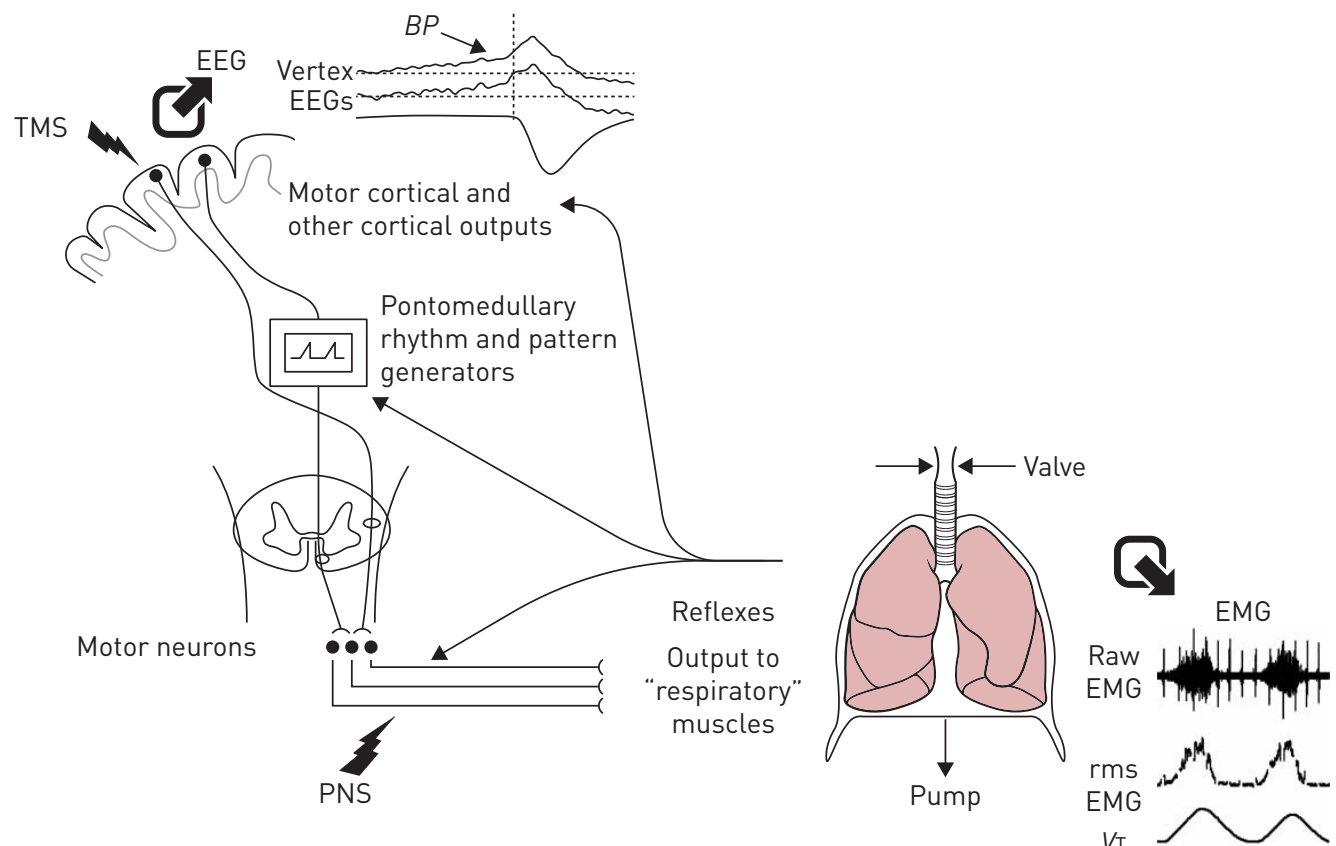

FIGURE 4 Neurophysiological techniques to assess respiratory muscle control. Schematic of the neural control of the human respiratory muscles. Multiple descending pathways integrate at the respiratory motor neurons (with reflex afferent inputs) and determine the functional output of the muscles. Using electromyography (EMG), the output can be measured during resting breathing, exercise and voluntary manoeuvres or as evoked signals in response to transcranial magnetic stimulation (TMS) over the motor areas or phrenic nerve stimulation (PNS) of the peripheral nerve. The output from cortical networks can be measured using electroencephalography (EEG) as the presence of a bereitschaft (readiness) potential (BP) indicates respiratory-related cortical activity. rms: root mean square; $V_{\mathrm{T}}$ : tidal volume. 


\section{Tests (EMG techniques) Main variables Reference values and}

\begin{tabular}{|c|c|c|c|c|c|c|}
\hline Tests (EMG techniques) & Main variables & $\begin{array}{l}\text { Reference values and } \\
\text { discriminative values }\end{array}$ & $\begin{array}{l}\text { Repeatability/reliability/ } \\
\text { validity }\end{array}$ & Cautions/safety & $\begin{array}{l}\text { Setting (clinical, } \\
\text { research) }\end{array}$ & Remarks \\
\hline \multirow{6}{*}{$\begin{array}{l}\text { EMG during breathing. } \\
\text { For surface and oesophageal } \\
\text { recordings, raw EMG or } \\
\text { integral/root mean square is } \\
\text { typically normalised to } \\
\text { maximal EMG measured } \\
\text { during maximal inspiratory } \\
\text { efforts (SNIP, PImax, } \\
\text { inspiration to TLC and MVV). } \\
\text { For the single motor unit } \\
\text { technique recorded with } \\
\text { needle or wire electrodes, } \\
\text { the peak discharge rate is } \\
\text { typically reported. }\end{array}$} & $\begin{array}{l}\text { sEMGpara, } \\
\text { EMGpara\%max }\end{array}$ & $\begin{array}{l}\text { Reference values for men and } \\
\text { women, with and without a } \\
\text { mouthpiece, raw versus } \\
\text { normalised signal [106]. }\end{array}$ & $\begin{array}{l}\text { Negligible bias for raw and } \\
\text { normalised EMG between } \\
\text { recording sessions. Small } \\
\text { bias in raw EMGpara for } \\
\text { repeat measures in the } \\
\text { same recording session } \\
\text { [106]. }\end{array}$ & $\begin{array}{l}\text { Considered safe except for small } \\
\text { chance of skin abrasion during } \\
\text { electrode preparation. } \\
\text { However, signal is subject to } \\
\text { contamination from other } \\
\text { muscle activity and movement } \\
\text { of muscle. }\end{array}$ & Clinical, research & $\begin{array}{l}\text { Recordings of sEMGpara show } \\
\text { promise as a noninvasive } \\
\text { method to measure neural } \\
\text { respiratory drive [104]. }\end{array}$ \\
\hline & sEMGscal & NA & $\begin{array}{l}\text { Ensemble average of } \\
80 \text { breaths had } \\
\text { comparable timing of } \\
\text { inspiratory activity as } \\
\text { iEMG recordings for } \\
3 \text { participants [307]. }\end{array}$ & & Research & $\begin{array}{l}\text { sEMGscal has been proposed } \\
\text { as a monitoring tool in the } \\
\text { ICU [100]. }\end{array}$ \\
\hline & sEMGdi & $\begin{array}{l}\text { NA for adults. Reference } \\
\text { values for children during } \\
\text { sleep [308]. }\end{array}$ & $\begin{array}{l}\text { Excellent reliability within } \\
\text { participants, and excellent } \\
\text { agreement between } \\
\text { occasions and between } \\
\text { observers, but data from } \\
\text { children who were } \\
\text { snorers [308]. }\end{array}$ & & Clinical, research & $\begin{array}{l}\text { Surface EMG over the chest } \\
\text { wall can be very susceptible } \\
\text { to contamination. }\end{array}$ \\
\hline & oesEMGdi\%max & $\begin{array}{l}\text { Reference values for young } \\
\text { (<50 years) and old } \\
\text { (>50 years) subjects. No } \\
\text { difference if signal } \\
\text { normalised to max in } \\
\text { voluntary manoeuvres or } \\
\text { evoked response (i.e. } \\
\text { oesCMAPdi) [103] }\end{array}$ & $\begin{array}{l}\text { Good repeatability between } \\
\text { recording sessions and } \\
\text { between observers [103]. }\end{array}$ & $\begin{array}{l}\text { Not for use in patients with } \\
\text { oesophageal varices. }\end{array}$ & $\begin{array}{l}\text { Clinical, } \\
\text { research. Used } \\
\text { in neutrally } \\
\text { adjusted } \\
\text { ventilatory } \\
\text { assistance. }\end{array}$ & $\begin{array}{l}\text { The preferred technique for } \\
\text { testing respiratory muscle } \\
\text { control during exercise given } \\
\text { its specificity and safety } \\
\text { advantages. Disadvantage of } \\
\text { the normalisation procedure } \\
\text { is that "maximal efforts" can } \\
\text { be, in fact, submaximal [309]. }\end{array}$ \\
\hline & iEMGdi & $\begin{array}{l}\text { No data available for amplitude } \\
\text { during quiet breathing. This } \\
\text { measure is typically used to } \\
\text { compare activity between } \\
\text { experimental procedures } \\
\text { [310]. }\end{array}$ & & $\begin{array}{l}\text { Usual considerations with needle } \\
\text { insertion (bleeding, pain and } \\
\text { infection). Risk of } \\
\text { pneumothorax can be } \\
\text { minimised with appropriate } \\
\text { precautions (e.g. ultrasound } \\
\text { and online audio/visual } \\
\text { feedback), but greater risk } \\
\text { during exercise due to } \\
\text { increased lung excursion and } \\
\text { chest wall movement. }\end{array}$ & Research & $\begin{array}{l}\text { Even intramuscular recordings } \\
\text { are susceptible to cross-talk } \\
\text { [311], although to a much } \\
\text { smaller degree than surface } \\
\text { recordings. Can be used for } \\
\text { single- or multi-unit } \\
\text { recordings. }\end{array}$ \\
\hline & SMUdi, SMUia & $\begin{array}{l}\text { Multiple studies in small } \\
\text { samples of healthy subjects } \\
\text { are available (refer to [93] } \\
\text { for references). }\end{array}$ & $\begin{array}{l}\text { Excellent validity given } \\
\text { recordings do not need to } \\
\text { be normalised, are much } \\
\text { less susceptible to } \\
\text { recordings artefacts. }\end{array}$ & Safety considerations as above. & $\begin{array}{l}\text { Used in research, } \\
\text { and } \\
\text { occasionally } \\
\text { clinically, in } \\
\text { expert centres. }\end{array}$ & $\begin{array}{l}\text { Recorded using needle or } \\
\text { selective wire electrodes. A } \\
\text { needle electrode can be } \\
\text { manipulated in the muscle to } \\
\text { sample populations of } \\
\text { respiratory motor units. }\end{array}$ \\
\hline
\end{tabular}




\begin{tabular}{|c|c|c|c|c|c|c|}
\hline Tests (EMG techniques) & Main variables & $\begin{array}{l}\text { Reference values and } \\
\text { discriminative values }\end{array}$ & $\begin{array}{l}\text { Repeatability/reliability/ } \\
\text { validity }\end{array}$ & Cautions/safety & $\begin{array}{l}\text { Setting (clinical, } \\
\text { research) }\end{array}$ & Remarks \\
\hline \multirow{2}{*}{$\begin{array}{l}\text { Evoked signals } \\
\text { Measured as the compound } \\
\text { muscle action potential in } \\
\text { response to electrical } \\
\text { stimulation or magnetic } \\
\text { stimulation over the cervical } \\
\text { spinal cord (CMS) or } \\
\text { anterolaterally on the neck } \\
\text { (unilateral; UMS) of the } \\
\text { phrenic nerve(s). }\end{array}$} & sCMAPdi & $\begin{array}{l}\text { Typically, latency } 6-8 \mathrm{~ms} \text {, } \\
\text { depending on stimulation } \\
\text { technique or side }[109,312] . \\
\text { Amplitude of CMAP more } \\
\text { variable. }\end{array}$ & $\begin{array}{l}\text { Latency is reproducible for } \\
\text { both electrical and } \\
\text { cervical magnetic } \\
\text { stimulation [109]. }\end{array}$ & $\begin{array}{l}\text { For magnetic stimulation, the } \\
\text { contraindications are listed in } \\
\text { the supplementary table. }\end{array}$ & $\begin{array}{l}\text { Both clinical } \\
\text { investigation } \\
\text { and research. }\end{array}$ & $\begin{array}{l}\text { Signal free of contamination if } \\
\text { phrenic nerve is activated } \\
\text { without co-stimulation of } \\
\text { other muscles. Usually used } \\
\text { to diagnose neuromuscular } \\
\text { diseases. }\end{array}$ \\
\hline & oesCMAPdi & $\begin{array}{l}\text { Using a multi-pair electrode, } \\
\text { latency is 6-8 ms [102, 313]. } \\
\text { Latency shorter on right cf. } \\
\text { left side and shorter } \\
\text { compared to sCMAPdi from } \\
\text { costal diaphragm [313]. } \\
\text { Amplitude of CMAP is more } \\
\text { variable [313]. }\end{array}$ & $\begin{array}{l}\text { Good reproducibility } \\
\text { between recording } \\
\text { sessions for latency [102, } \\
\text { 313]. Good agreement } \\
\text { between electrical and } \\
\text { unilateral magnetic } \\
\text { stimulation for latency } \\
\text { and amplitude [102]. }\end{array}$ & $\begin{array}{l}\text { Safety considerations for } \\
\text { magnetic stimulation as above. } \\
\text { Oesophageal catheter not for } \\
\text { use in patients with } \\
\text { oesophageal varices. }\end{array}$ & $\begin{array}{l}\text { Clinical, } \\
\text { research. }\end{array}$ & \\
\hline
\end{tabular}

s: surface recordings; ia: intercostal/accessory muscles; oes: oesophageal; para: parasternal intercostal muscle of the second interspace; scal: scalene muscle; di: diaphragm; \%max: as a percentage of maximal EMG; SNIP: sniff nasal inspiratory pressure; PImax: maximal inspiratory pressure; TLC: total lung capacity; MVV: maximal voluntary ventilation; ICU: intensive care unit; SMU: single motor unit; CMS: cervical magnetic stimulation; UMS: unilateral magnetic stimulation; CMAP: compound muscle action potential; NA: not applicable. 
cortico-subcortical networks are also engaged in situations where the breathing control system is challenged. Thus, a cortical drive to breathe contributes to the maintenance of ventilatory activity during wakefulness, in spite of profound hypocapnia [134]. Respiratory-related cortico-subcortical networks are also activated when the respiratory system is faced with mechanical constraints [128, 135-138]. This activation is not only sensory, but also motor. A motor respiratory-related cortical activity has been described in various clinical situations. Patients with deficient respiratory automaticity due to Phox 2B mutations (congenital central alveolar hypoventilation) exhibit respiratory-related cortical activity on their electroencephalograms during resting breathing [139]. Detailed observations made in one such patient showed better cognitive performance during mechanical ventilation than during unsupported breathing [140]. This finding lends support of the actual role of the cortical activity in sustaining ventilation ("dual tasking paradigm" [141]). A similar cortical activity has been described in patients with severe forms of the obstructive sleep apnoea syndrome (OSAS) [142] (probably related to the inspiratory load induced by upper airway abnormalities) and in patients with inspiratory muscle weakness due to ALS [143]. Experimental and clinical data are therefore consistent with the notion that the respiratory-related cortical networks provide cortico-medullary co-operation when automatic breathing is compromised. Activation of respiratory-related cortical networks in response to experimental loading is accompanied by respiratory discomfort [137, 138, 143]. In patients with diaphragm dysfunction, alleviating dyspnoea by mechanical ventilatory assistance silences respiratory-related cortical activity [143], suggesting a causative relationship. These observations have led to the hypothesis that respiratory-related EEG activity could constitute a surrogate for self-reported dyspnoea in patients unable to directly communicate with their caregivers, thus forming the basis for a patient-ventilator interface [144]. Of note, the motor cortical activities related to breathing are not synonymous of breathing discomfort (e.g. voluntary respiratory manoeuvres), and it must be kept in mind that the brain correlates of breathing discomfort are numerous, very complex and mostly sensory in nature (as exemplified by a host of specific studies that are beyond the scope of this statement).

\subsection{Transcranial magnetic stimulation}

Transcranial magnetic stimulation (TMS) is a widely used noninvasive neurophysiological technique to assess the excitability of the cerebral cortex and of the corticospinal tract in vivo (table 4) [145].

TMS causes no long-term adverse effects in healthy subjects. High frequency $(1-50 \mathrm{~Hz})$, high-intensity repetitive TMS (rTMS), however, has the potential to induce epileptic seizures even in healthy individuals [146]. This can be minimised by careful selection of subjects [147] and stimulus threshold, and strict adherence to the available safety guidelines (table 5, table S12) [55].

The validity of TMS critically depends on the appropriate location of EMG electrodes [148] and control of background muscle activity and noise. In the research laboratory, single- and paired-pulse TMS have been used to document and describe the corticospinal pathway to the diaphragm at rest and during different physiological conditions in healthy subjects (supplementary material) [149-151]. In the clinical field, TMS has been used to document the involvement of the respiratory muscles in patients with neurological conditions, such as stroke and multiple sclerosis [152-154] (table S13).

Test-retest reliability of TMS for respiratory muscles are not available. These data for limb muscles are summarised in table 5 .

Results mostly from upper airway and diaphragm muscles in response to TMS are documented. Widespread disease-related alteration of corticomotor excitability (as documented by changes in a hand muscle) could also indirectly influence respiratory muscle control and are summarised in the table S13.

In OSAS patients, genioglossus central motor conduction time (CMCT) closely correlates with severity of disease [155]. An increase in cortical-motoneuronal excitability is observed in the genioglossus and diaphragm muscles of awake OSAS patients [155, 156], but not for submental muscles [157, 158]. No plasticity-related changes in genioglossus cortical activity is observed in response to rTMS trains [159, 160].

In stable patients with COPD, intracortical facilitation (ICF) of the diaphragm correlates with inspiratory muscle strength, whereas intracortical inhibition correlates with arterial partial pressure of $\mathrm{CO}_{2}$ [161]. In COPD, the corticospinal pathway to the diaphragm is more excitable and intracortical facilitation of the diaphragm is markedly attenuated compared to healthy subjects [162].

In the ICU, diaphragm response to TMS in patients with central ventilatory paralysis (e.g. cervical spinal cord lesions) predicts the recovery of spontaneous ventilation within 1 year [163]. In patients with stroke, the respiratory system response to TMS represents a simple bedside technique to assess airway clearance and evaluate aspiration risk [164].

For the use of TMS to evaluate interventions, please refer to table S13. 
TABLE 5 Characteristics of transcranial magnetic stimulation (TMS) paradigms and related measures

paradigms)

Main measures Definition

Physiological significance

Repeatability/reliability/validity

Safety

Setting

Iclinical,

Single-pulse Noninvasive and painless neurophysiological

TMS

technique to evaluate the excitability of

motor cortical area and the cortical spinal

pathways conductivity through the

administration of magnetic stimuli over

the scalp.

$\begin{array}{cc}\begin{array}{c}\text { Motor evoked } \\ \text { potential (MEP) }\end{array} & \text { TMScular response obtained after a single } \\ & \text { TMS applied over the contralateral }\end{array}$ TMS pulse applied over the contralateral

stimulation intensity.

MEP latency

Time interval between the application of the TMS pulse on the motor cortex area and MEP onset from the contralateral target muscle; it reflects the conductivity of both the central and peripheral nervous systems, as well as neuromuscular junctions and muscles.

MEP amplitude Amplitude of MEP response measured peak-to peak. It reflects the excitatory state of output cells in the motor cortex, nerve roots and the conduction along the peripheral motor pathway to the muscles.

$\begin{array}{cc}\text { Resting motor } & \text { Lowest TMS intensity able to evoke MEPs i } \\ \text { threshold (RMT) } & \text { the resting target muscle when }\end{array}$

single-pulse stimuli are applied to the motor cortex.

Reflects the excitability of a central core of neurons, which arises from the membrane excitability and a balance

between inhibitory and excitatory input from local circuits.

Active motor Lowest TMS intensity required to obtain a threshold (AMT) MEP response during a weak muscle contraction.

Cortical silent Period of suppression of EMG activity period (CSP) following a twitch suprathreshold TMS stimulus of a target muscle during a sustained voluntary contraction of this muscle.

Central motor Latency difference between the MEPs conduction time induced by TMS and by peripheral (motor (CMCT) root) stimulation. and excitability of the corticospinal system.

Cortico (spinal) inhibitory mechanisms, possibly GABAb mediated (but not only).

Reflects the integrity of the cortical-spinal tract, from the upper to the lower moto
Integrity of the corticospinal tract Moderate to good reliability for MEP amplitude of FDI muscle at rest and under active condition; MEP amplitude is more reliable at $120 \%$ intensity of stimulation than those obtained at $100 \%$ [315].

Carries little risk beyond occasiona local discomfort at the site of stimulation or a transient headache in susceptible subjects. No change in blood pressure, heart rate, EEG serum prolactin level, serum cortisol level, or in a variety of memory, cognitive, learning, sensory and motor tests [314] long-term interval [315], also in

[317].

Good to excellent short- and

Research

long-term reliability in FDI [315].

Research

[315] and FDI [317].

Research neurons. 


\begin{tabular}{|c|c|c|c|c|c|c|}
\hline $\begin{array}{l}\text { Tests (TMS } \\
\text { paradigms) }\end{array}$ & Main measures & Definition & Physiological significance & Repeatability/reliability/validity & Safety & $\begin{array}{l}\text { Setting } \\
\quad \text { (clinical, } \\
\text { research) }\end{array}$ \\
\hline \multirow[t]{3}{*}{$\begin{array}{l}\text { Paired-pulse } \\
\text { TMS }\end{array}$} & & $\begin{array}{l}\text { TMS paradigm to study intracortical } \\
\text { inhibitory and excitatory phenomena by } \\
\text { means of a conditioning subthreshold } \\
\text { stimulus preceding a suprathreshold test } \\
\text { stimulus applied at different interstimulus } \\
\text { interval. }\end{array}$ & & & & Research \\
\hline & $\begin{array}{l}\text { Intracortical } \\
\quad \text { facilitation (ICF) }\end{array}$ & $\begin{array}{l}\text { Paired-pulse TMS measure obtained with } \\
\text { long interstimulus interval where the } \\
\text { conditioning stimulus is followed by an } \\
\text { enhanced response with respect to the } \\
\text { test stimulus; it is modulated by multiple } \\
\text { neurotransmission pathways. }\end{array}$ & $\begin{array}{l}\text { Expresses the activity of } \\
\text { glutamatergic excitatory } \\
\text { circuits }\end{array}$ & Poor reliability in ADM [315]. & & Research \\
\hline & $\begin{array}{l}\text { Short latency } \\
\text { intracortical } \\
\text { inhibition (SICI) }\end{array}$ & $\begin{array}{l}\text { Paired-pulse TMS measure obtained with } \\
\text { short interstimulus interval where the } \\
\text { conditioning stimulus is followed by an } \\
\text { inhibition with respect to the test stimulus; } \\
\text { it is attributed to an activation of inhibitory } \\
\text { neuronal system transmission. }\end{array}$ & $\begin{array}{l}\text { Reflect the activity of GABAergic } \\
\text { inhibitory circuits }\end{array}$ & $\begin{array}{l}\text { Good short-term and long-term } \\
\text { reliability under resting, not for } \\
\text { active conditions [315]. }\end{array}$ & & Research \\
\hline \multirow[t]{4}{*}{$\begin{array}{l}\text { Repetitive } \\
\text { TMS (rTMS) }\end{array}$} & rTMS & $\begin{array}{l}\text { Train of TMS pulses of the same intensity } \\
\text { applied at a given frequency to a given } \\
\text { brain area, that can transiently influence } \\
\text { the function of stimulated and connected } \\
\text { brain areas, mainly dependent on } \\
\text { stimulation frequency. }\end{array}$ & & & $\begin{array}{l}\text { Even in normal subjects, prolonged, } \\
\text { high intensity, rTMS at } 10-25 \mathrm{~Hz} \\
\text { rates can produce partial seizures } \\
\text { with or without secondary } \\
\text { generalisation [146]. Short } \\
\text { inter-train intervals can cause } \\
\text { transient degradation in short term } \\
\text { verbal memory immediately } \\
\text { following rTMS [318]. }\end{array}$ & Research \\
\hline & $\begin{array}{l}\text { Low-frequency } \\
\text { rTMS }\end{array}$ & $\begin{array}{l}\text { Trains of variable duration at } \leqslant 1 \mathrm{~Hz} \\
\text { stimulation frequency. }\end{array}$ & $\begin{array}{l}\text { Depression of the excitability of } \\
\text { the stimulated regions, } \\
\text { possibly via LTD. }\end{array}$ & & & Research \\
\hline & $\begin{array}{l}\text { High-frequency } \\
\text { rTMS }\end{array}$ & $\begin{array}{l}\text { Trains of variable duration at } \geqslant 1 \mathrm{~Hz} \\
\text { stimulation frequency. }\end{array}$ & $\begin{array}{l}\text { Increase of the excitability of the } \\
\text { stimulated regions, possibly via } \\
\text { LTP. }\end{array}$ & & & Research \\
\hline & $\begin{array}{l}\text { Theta burst } \\
\text { stimulation } \\
\text { (TBS) }\end{array}$ & $\begin{array}{l}\text { A form of complex rTMS trains combining } \\
\text { different frequencies (i.e. } 50 \mathrm{~Hz} \\
\text { pulse-trains repeated at a rate of } 5 \mathrm{~Hz} \text { ) } \\
\text { with after-effects on cortical-spinal and } \\
\text { cortical-cortical excitability that may } \\
\text { reflect changes in synaptic plasticity. }\end{array}$ & Inhibition when higher than $1 \mathrm{~Hz}$. & & & Research \\
\hline
\end{tabular}




\section{Section 3. Respiratory muscle imaging}

\subsection{Ultrasound}

Since the publication of the previous ATS/ERS statement [1], numerous studies have reported on the use of ultrasound to assess diaphragm dimensions and activity. With the increasing availability of ultrasound at the bedside, this technique allows a simple, rapid and direct evaluation of the diaphragm that is more sensitive than fluoroscopy for the identification of muscle activity [165].

The most frequently assessed variables using diaphragm ultrasound are: 1) static measurement of end-expiratory diaphragm thickness $(\mathrm{Tdi}) ; 2$ ) dynamic evaluation of the ratio of inspiratory to expiratory diaphragm thicknesses, reported as thickening ratio (TR; inspiratory thickness/expiratory thickness) or thickening fraction (TF; (inspiratory thickness - expiratory thickness)/end-expiratory thickness); and 3) diaphragmatic excursion [166]. Measurements of Tdi and TF are performed by placing a high-frequency linear probe at the level of the zone of apposition, while diaphragm excursion is measured using a curvilinear probe placed in the subcostal region and recording diaphragm movements in M-mode (figure 5).

\subsubsection{Diaphragm thickness}

In healthy subjects at rest, intra- and inter-observer reliability of Tdi are high [167-171] and ultrasound estimates of Tdi are correlated to direct anatomical measurements [168]. The lower limit of normal for Tdi has been reported to be $0.15 \mathrm{~cm}$ in healthy subjects, with a wide baseline range of values [167]. Similar values have been reported for patients with COPD [172]. It is unclear whether a Tdi value below this threshold can be used to identify diaphragm dysfunction. Tdi does not seem to change with age [167] but can be influenced by posture [173], stature [171, 174] and body composition [171, 175]. In addition, in studies of patients with diaphragm weakness, a large proportion of subjects had Tdi values of $0.15 \mathrm{~cm}$ [176-178]. However, the temporal evolution of $\mathrm{Tdi}$ in these patients was related to the change in $\mathrm{VC}$ in those with recovery of diaphragm function [176]. This observation suggests that Tdi can be used to monitor the evolution of diaphragm weakness [176]. In mechanically ventilated patients, Tdi is reproducible [179, 180]. Tdi is not correlated with $P$ ao,tw when patients are receiving assist control ventilation or pressure support ventilation [181]. Tdi is a poor predictor of weaning outcome [182-184]. Finally, over the course of mechanical ventilation, Tdi can decrease, increase or remain unchanged $[185,186]$.

\subsubsection{Diaphragm thickening fraction and ratio}

The measurement of TF is reproducible [179], with a reported lower limit of normal of $20 \%$ in healthy subjects and patients with COPD $[167,172]$. A TF around $20 \%$, however, is possibly more closely associated with near complete paresis rather than partial dysfunction, as the mean values for TF in healthy subjects can frequently exceed $100 \%$ [167].

Diaphragmatic contractions produce both muscle shortening and thickening. The correlation between diaphragm thickening and diaphragm effort, however, is tenuous: ultrasound measurements of diaphragm

a)

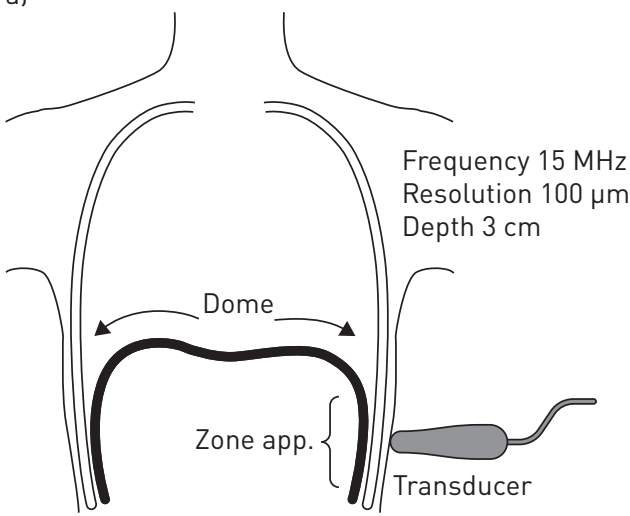

b)

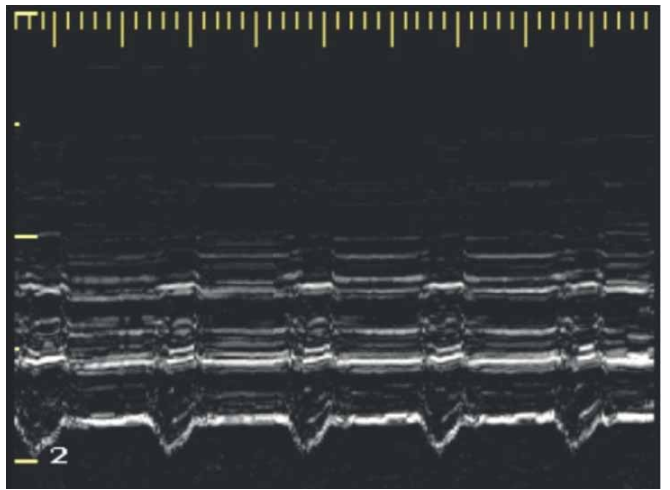

FIGURE 5 Diaphragm ultrasound assessment. a) When measuring diaphragm thickness and thickening fraction, the use of a linear, high-frequency probe is suggested. The probe is positioned in the sagittal-oblique position at the level of the zone of apposition, and image scanning begins at the mid-axillary line. When evaluating diaphragm excursion, use of a curvilinear, low-frequency probe is preferable. The probe is positioned in the sub-hepatic region, with the beam oriented cephalad and posteriorly, aiming at the most cephalad aspect of the diaphragmatic dome. b) M-mode image of diaphragm thickening during inspiration. End-expiratory and end-inspiratory diaphragm thicknesses can be directly measured and thickening fraction can be determined. 
thickening explain only one third (or less) of the variability in inspiratory effort $[180,187,188]$. This is not surprising, considering that thickening is a one-dimensional measurement, whereas inspiratory effort results from an active three-dimensional displacement of muscle volume. In addition, the extent of diaphragm thickening for a given level of inspiratory effort varies considerably between subjects and the reproducibility of the measurement is weak (reproducibility coefficients range from $16 \%$ to $27 \%$ ) [187].

In critically ill patients receiving pressure support ventilation, $\mathrm{TF}<29 \%$ has been associated with diaphragm dysfunction, the latter being defined as $P$ ao,tw $<11 \mathrm{cmH}_{2} \mathrm{O}$ [181]. In addition, diaphragm TF moderately correlates to indices of neural respiratory drive such as $P_{0.1}$ [188] and has been reported as a possible predictor of weaning outcome [181, 182, 189] and duration of mechanical ventilation [181, 189]. In patients with acute exacerbation of COPD, preliminary data suggests that TF is related to failure of noninvasive ventilation and mortality [190]. Measurements of expiratory and inspiratory diaphragm thickness can be performed using either B- or M-mode ultrasound. The use of M-mode offers the theoretical advantage of making the recording of both variables in a single inspiratory/expiratory cycle easier, and the manual measurement of diaphragm thickness on the same ultrasound frozen image. Whether this translates into a clinically significant difference in measurement compared with B-mode remains to be determined. No studies have yet evaluated TF or TR during exercise.

\subsubsection{Diaphragm excursion}

Excursion of the right diaphragm has high intra- and inter-observer reliability [191, 192] and its lower limit of normal is $3.6 \mathrm{~cm}$ in women and $4.7 \mathrm{~cm}$ in men during maximal inspiratory efforts [191]. From a technical point of view, measurement errors may occur when the displacement of the diaphragm is not optimally aligned with the M-mode plane, but angle-independent M-mode sonography may mitigate this effect [193].

Diaphragm excursion is sensitive to changes in respiratory pattern [194], is related to the volume-generating capacity of the diaphragm (measured using VC) following abdominal surgery [195] and has been used to identify diaphragm weakness in the setting of acute exacerbation of COPD [196] and acute stroke [197]. In intubated patients, diaphragm excursion is moderately related to Pdi [198] and, possibly, to weaning outcome [192, 199]. In children, ultrasound imaging has been used to assess anatomical defects of the diaphragm (lobulated-shaped hemidiaphragms, focal diaphragmatic eventration, diaphragmatic hernia) and to document paradoxical movements of the diaphragm (supplementary material) [200].

\subsection{Optoelectronic plethysmography}

Optoelectronic plethysmography (OEP) is an established technique that allows tidal changes in the volume of the chest wall and its compartments to be measured (figure 6) [201, 202]. By using this technique, investigators reported that patients with more severe COPD consistently experience dynamic hyperinflation during incremental exercise, while other patients, specifically those with a greater expiratory flow reserve at rest, adopted at least two significantly different patterns of change in end-expiratory volume of the chest wall [203-205]: some showed a progressive significant increase in end-expiratory volume of the chest wall ("early hyperinflators") and others showed an increase only at higher levels of exercise ("late hyperinflators"). Three different, distinct patterns of breathing and chest wall volume displacement were found in patients with severe COPD, interstitial pulmonary fibrosis and cystic fibrosis to cope with chronic respiratory failure [206].

OEP has been used to evaluate a variety of NMDs, such as Duchenne [207-209], limb girdle and Becker muscular dystrophies, facioscapulohumeral dystrophy [210] and ALS [211]. OEP has also been used to assess the effects of different surgical techniques (such as laparoscopic surgery) on chest wall kinematics and inspiratory muscle activity [212], Nuss technique for pectus excavatum [213], diaphragm plication for unilateral diaphragm paralysis [214], and diaphragm repair in congenital diaphragmatic hernia [215]. More recently, OEP has been used to evaluate the effects on chest wall kinematics of several interventions, such as air stacking [216], breath stacking [217], stretching [218], incentive spirometry [219], inspiratory loaded breathing [220] and rehabilitation [221]. OEP can be used to monitor tidal breathing and respiratory muscle function in newborns [222], in children with spinal muscle atrophy type 1 and type 2 [223] and in children and young adults with Duchenne muscular dystrophy [207, 208].

\subsection{Other investigations}

Chest radiography and computed tomography have been used to assess the position of the diaphragm, particularly to identify diaphragm elevation secondary to weakness or paralysis in patients with myopathies, neuropathies and injured hemidiaphragm [224]. Chest fluoroscopy, although highly ionising, has been used to identify decreased or paradoxical diaphragm motion. 


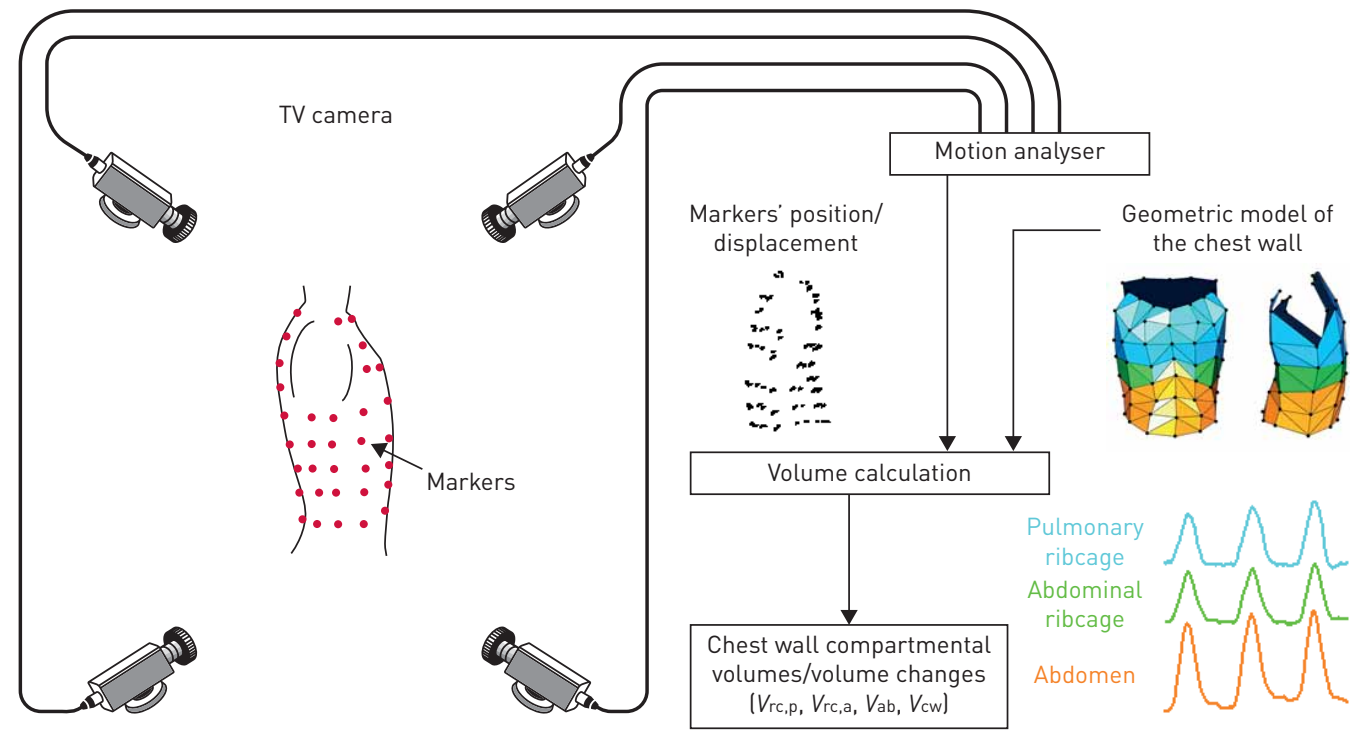

FIGURE 6 Optoelectronic plethysmography. A number of reflective markers are positioned on the trunk of the subject in selected anatomical reference sites of the ribcage and the abdomen. A set of cameras placed nearby the subject under analysis and dedicated stereo-photogrammetric techniques allow measuring the position (three-dimensional coordinates) and motion of the markers. A closed surface is defined by connecting the points and the volume enclosed by the thoraco-abdominal surface and its different parts is computed using Gauss' theorem. The chest wall is typically modelled as being composed of three different compartments: pulmonary ribcage (rc,p), exposed on its inner surface to pleural pressure, abdominal ribcage $(r c, a)$, and the abdomen $(a b)$, the latter both exposed to abdominal pressure. Total chest wall volume $\left(V_{c w}\right)$ is the sum of the volume of these three compartments (Vrc,p, $V_{r c, a}$ and $V_{a b}$ ).

Two- and three-dimensional magnetic resonance imaging (MRI) is being increasingly used, particularly in neuromuscular diseases [224], to assess muscle size, structure and altered function by using different tissue-weighting (T1, T2 and proton density). Two-dimensional MRI can assess qualitatively muscular atrophy on axial and coronal images and measure the cranio-caudal diaphragm movement. Dynamic MRI provides information on the motion of the chest wall and the diaphragm on sagittal images [225]. Given the paucity of published studies on this topic, it is difficult to draw conclusions on this imaging tool; further studies are needed to evaluate the validity, precision, reproducibility, prognostic value and responsiveness to interventions of dynamic MRI of the diaphragm.

Structured light plethysmography (SLP) is another emerging imaging tool. SLP is a non-contact, noninvasive method to assess breathing pattern [226]. The technique is based on the stereoscopic analysis of respiratory-related distortions of a black and white chequered pattern projected on the chest wall and abdomen [226-228]. SLP has been validated in healthy subjects and in patients [226-229]. In a recent study, NIERAT et al. [226] reported that SLP can detect differences in breathing pattern in COPD compared with healthy controls. In the same study, SLP allowed measurement of ventilatory activity while preserving resting tidal breathing variability, reducing instrumental observer effect and avoiding any disruptions in breathing pattern induced by the use of the pneumotachograph-mouthpiece-noseclip combination. SLP allows a detailed compartmentalised analysis of thoraco-abdominal behaviour, which is not the case for wearable devices [226]. In children with asthma, SLP can differentiate those with and without airway obstruction, and may identify responses to bronchodilator [230]. Further research is, however, required to confirm the clinical applications of SLP.

\section{Section 4. Respiratory muscle structure, perfusion and metabolism}

Several methodological approaches can provide a comprehensive assessment of the mechanisms regulating respiratory muscle blood flow and oxygen delivery in relation to oxidative metabolic demand and mitochondrial function, as well as the consequences of oxidative stress and inflammation (table 6). These techniques have the potential to be used for monitoring interventions aimed at restoring respiratory muscle function in the ICU and the rehabilitation setting.

\subsection{Near-infrared spectroscopy}

A decade ago, a technique combining near-infrared spectroscopy (NIRS) with the light absorbing tracer dye indocyanine green (ICG) was employed to measure intercostal muscle blood flow (IMBF) using Fick's 
TABLE 6 Laboratory techniques for evaluation of respiratory muscle structure, perfusion and metabolism

\begin{tabular}{|c|c|c|c|c|}
\hline Techniques & Invasiveness & $\begin{array}{l}\text { Physiology laboratory } \\
\text { required }\end{array}$ & $\begin{array}{l}\text { Biology laboratory } \\
\text { required }\end{array}$ & Purpose \\
\hline Near-infrared spectroscopy & None & Yes & No & Muscle blood flow \\
\hline Oxygen cost of breathing & None & Yes & No & Ventilation, oxygen uptake \\
\hline Access to costal diaphragm muscle & Yes, thoracotomy & $\begin{array}{l}\text { Yes, always in } \\
\text { surgery room }\end{array}$ & No & $\begin{array}{l}\text { Biological and histological } \\
\text { analyses }\end{array}$ \\
\hline Access to parasternal muscles & Yes, thoracotomy & $\begin{array}{l}\text { Yes, always in } \\
\text { surgery room }\end{array}$ & No & $\begin{array}{l}\text { Biological and histological } \\
\text { analyses }\end{array}$ \\
\hline Access to external intercostals & Yes, open biopsy techniques & $\begin{array}{l}\text { Yes, possible in } \\
\text { surgery room }\end{array}$ & No & $\begin{array}{l}\text { Biological and histological } \\
\text { analyses }\end{array}$ \\
\hline $\begin{array}{l}\text { Immunohistochemical or } \\
\text { immunofluorescence analyses }\end{array}$ & & No & Yes & $\begin{array}{l}\text { Muscle fibre type and } \\
\text { morphometry }\end{array}$ \\
\hline $\begin{array}{l}\text { Mitochondrial respiratory chain } \\
\text { evaluation (respiration procedures) }\end{array}$ & None & No & Yes & $\begin{array}{l}\text { Quantification of mitochondrial } \\
\text { respiration (oxygen consumption) }\end{array}$ \\
\hline Immunoblotting procedures & None & No & Yes & $\begin{array}{l}\text { Quantification of protein levels in } \\
\text { muscle specimens }\end{array}$ \\
\hline Quantitative real-time PCR & None & No & Yes & $\begin{array}{l}\text { Quantification of gene expression } \\
\text { levels in muscle specimens }\end{array}$ \\
\hline $\begin{array}{l}\text { Specific activity assays including } \\
\text { mitochondrial enzyme activities }\end{array}$ & None & No & Yes & $\begin{array}{l}\text { Quantification of activity levels of } \\
\text { enzymes in muscle specimens }\end{array}$ \\
\hline
\end{tabular}

principle. GuenetTe et al. [231] were the first to quantify IMBF in healthy subjects during resting isocapnic hyperpnoea at different fractions of MVV. They reported that as ventilation rose, IMBF significantly correlated with the increase in cardiac output, WOB and Pdi, suggesting that the NIRS-ICG technique is a sensitive indicator of IMBF in healthy humans. Similar results have been reported by Vogiatzis and co-workers, employing the same NIRS-ICG technique to measure IMBF in healthy subjects [232] and COPD patients [233].

Absolute IMBF measurements via the NIRS-ICG technique require arterial cannulation. For this reason, an alternative method was proposed to measure relative changes in muscle perfusion from rest, namely the blood flow index (BFI), requiring only venous catheterisation for the injection of ICG (figure 7) [234].

HAвAZETTL et al. [234] compared BFI values obtained from the seventh intercostal space against absolute muscle blood flow determined using the NIRS-ICG technique during cycling in healthy subjects. The investigators reported a very good agreement between BFI and NIRS-ICG techniques in healthy subjects during cycling [234], and also (by retrospective data analysis) in patients with COPD (figure 7) [233]. GUENETTE et al. [235] showed that BFI of intercostal and sternocleidomastoid muscles during isocapnic hyperpnoea was strongly correlated with WOB and surface EMG, thus confirming that the BFI technique provides a minimally invasive and technically less demanding alternative to NIRS-ICG for measuring respiratory muscle perfusion in humans at rest and during exercise.

\subsection{Oxygen cost of breathing}

The oxygen cost of breathing is an index of the energy required for ventilation. For more detailed information on methods of assessment please refer to the supplementary material. Oxygen cost of breathing was shown to be increased in women [236, 237] and in obesity [238, 239], post-operative patients [240], COPD [240, 241], cystic fibrosis [242, 243], children with asthma [244], sarcoidosis [245] and chronic heart failure [246, 247]. In these conditions, the increased oxygen cost of breathing may contribute to increased energy cost during activities of daily living adding, particularly in diseases imposing a ventilator or cardiac constraint, an extra contribution to the reduced exercise capacity. Several interventions have been used in different patient populations to reduce WOB, which has a potential impact on reducing the oxygen cost of breathing, namely, invasive and noninvasive ventilation [248-250], high flow nasal oxygen [248, 251], ventilation with heliox [252], respiratory muscle training [253, 254] and exercise training [255].

\subsection{Biopsy (specificities for respiratory muscles)}

In recent years, respiratory muscles have been studied through the analyses of the costal diaphragm, with very restricted access, and only via thoracotomy performed for clinical reasons (mainly lung cancer and lung volume reduction surgeries). During thoracotomy, parasternal and diaphragm biopsy specimens have been obtained from the third interspace and the anterior costal diaphragm lateral to the insertion of the phrenic nerve, respectively [256-260]. Additionally, other studies have been based on the analysis of the 
a)

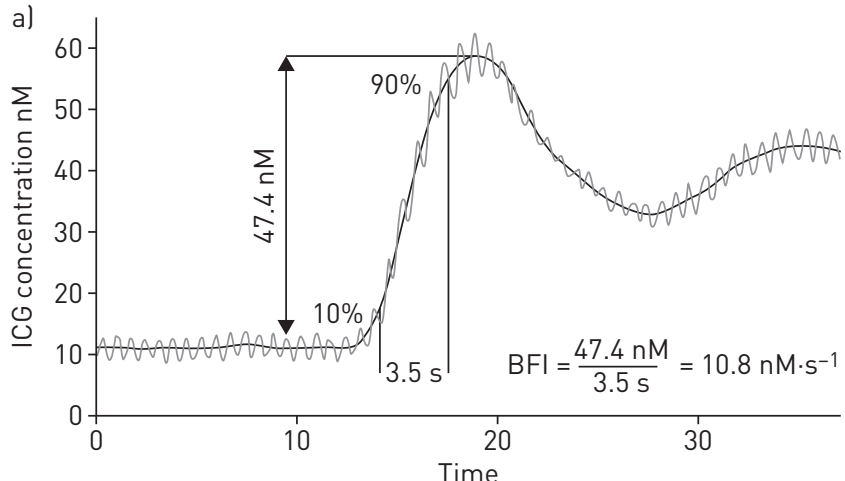

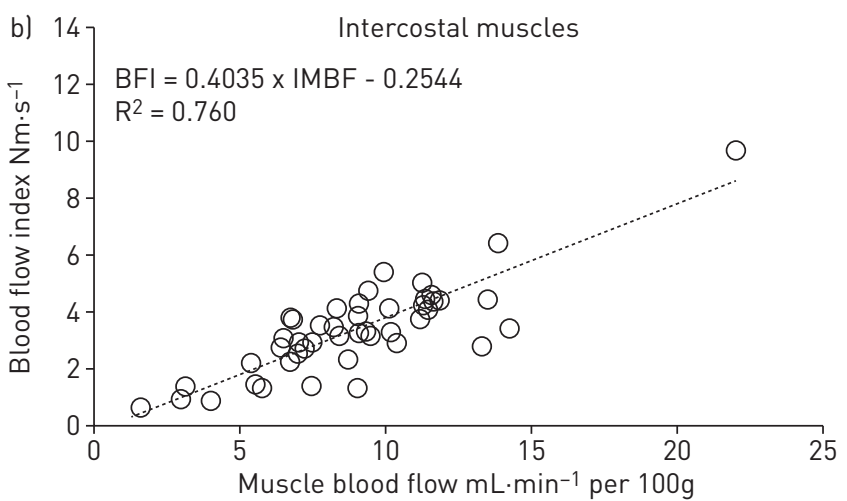

FIGURE 7 Near-infrared spectroscopy (NIRS). a) Typical example of muscle indocyanine green (ICG) concentration curve recorded by NIRS during exercise. The original tracing (grey line) appears with marked oscillations (at a frequency of $84 \mathrm{~min}^{-1} ; 1.4 \mathrm{~Hz}$ ) due to muscle contraction and relaxation during cycling. Low-pass filtering with a cut-off frequency of $0.5 \mathrm{~Hz}$ produced the smoothed curve (black line) that was used for blood flow index (BFI) calculation. Data points at 10 and $90 \%$ of ICG concentration peak are indicated, and an example of BFI calculation is given. Reproduced with permission from the publisher [234]. b) Regression analysis of individual BFI assessed by the NIRS-ICG method versus actually measured muscle blood flow assessed by Fick's principle at different levels of minute ventilation recorded during isocapnic hyperpnoea trials for the intercostal muscles in chronic obstructive pulmonary disease. IMBF: intercostal muscle blood flow. Data calculated from [233].

external intercostal muscle following procedures involving an open biopsy technique [257, 258, 261-265]. Biopsies from the external intercostals have usually been taken along the anterior axillary line at the sixth intercostal space, as detailed in previous studies [257, 258, 261-265]. In patients with chronic respiratory conditions, limb muscles are more severely affected than respiratory muscles, which need to overcome the increased inspiratory loads and may exhibit adaptive features [266].

\subsection{Typology}

Respiratory muscles undergo a series of structural changes in lung diseases. These changes have been extensively studied in patients with COPD, in which the diaphragm shows increased type I fibres [267], favouring aerobic metabolism [268]. Structural changes in the respiratory muscles (injury and regeneration cycles) depend mainly on the effect derived from increased ventilatory loads [269, 270]. Increases in capillary and mitochondria numbers and sarcomere length have also been demonstrated [271], along with sarcomere and sarcomeric damage and greater friability of diaphragm [272]. Diaphragm atrophy in patients with COPD has been reported by some, but not all, investigators [256, 259, 273, 274]. Changes in the proportions of fibre types have also been observed in the parasternal and external intercostal muscles of COPD patients $[257,275]$. In the latter muscles, an increase in capillary numbers was also described [276], together with fibre atrophy [277]. Respiratory muscle training increased fibre sizes and proportions of type I fibres [278]. In OSAS patients, increased proportions of type I fibres have been reported in the intercostal muscles [262], while no data is available for the diaphragm. Prolonged mechanical ventilation induces sarcomere damage and fibre atrophy in the diaphragm, with no relevant changes in fibre type proportions $[279,280]$.

\subsection{Mitochondrial function}

In rats, mitochondrial respiratory rates are lower in the diaphragm than in peripheral muscles [281]. In mice, hypoxia differentially affected peripheral and respiratory muscles with decreased mitochondrial content due to reduced mitochondrial biogenesis and increased mitophagy [282].

Mitochondrial function is altered in patients with COPD [260, 283, 284]. In these patients, mitochondria isolated from intercostal muscles demonstrate electron transport blockade and excessive production of reactive oxygen species, similar to effects found in the vastus lateralis $[259,284]$. In the diaphragm, overall mitochondrial respiratory chain capacity was increased and had a higher efficiency in patients with moderate [285] and severe [286] COPD than in healthy controls. In patients with COPD the oxidative capacity of the diaphragm is greater than that of the peripheral muscles [258].

Mitochondrial function and content are impaired in patients with sepsis [287]. In turn, animal models of prolonged mechanical ventilation demonstrate only minor changes in oxidative phosphorylation coupling in diaphragmatic mitochondria [288]. Attempts to improve mitochondrial function using anabolic steroids failed in a hamster model of emphysema [289]. Increased mitochondrial enzyme activity was shown in rodent diaphragm in response to endurance training [290]. 


\subsection{Oxidative stress}

Increased oxidant production has been reported in mitochondria and membrane compartments of diaphragm fibres in patients with severe COPD [256, 259]. In several studies [256, 259, 291, 292], the diaphragm of these patients exhibited increased levels of oxidative stress. Such levels inversely correlated with global respiratory and diaphragm muscle function among patients with more severe disease [256, 259]. Contractile actin and myosin, creatine kinase, and carbonic anhydrase- 3 are oxidatively modified in the diaphragm of patients with severe COPD, while protein content of myosin $[259,291,292]$ and creatine kinase and its activity are reduced [259]. Nonetheless, in saponin-skinned diaphragm and intercostal muscle fibres $[265,286]$, creatine kinase activity levels do not differ between severe COPD and healthy controls. In external intercostals of COPD patients [264] and in those with OSAS, oxidative stress levels are increased and treatment with continuous positive airway pressure for 6 months does not reduce those levels [262]. In external intercostal muscles of patients with severe sepsis, oxidative stress levels do not differ from those in controls [264]. Oxidative stress in the diaphragm of critically ill patients receiving mechanical ventilation is increased compared to controls [280, 293, 294]. In elderly subjects, markers of oxidative stress are increased in the external intercostals compared to young controls [261].

\subsection{Inflammation}

Systemic inflammation is a contributor of muscle dysfunction in COPD [295]. In contrast, local inflammation does not play a role in COPD muscle dysfunction: inflammatory cell counts were very low in the diaphragm and external intercostals of patients with severe COPD with preserved body composition [257]. Expression of mRNA and protein content of tumour necrosis factor alpha and interleukin-6 are greater in the external intercostals of patients with severe COPD and normal weight than in healthy controls, while muscle mRNA levels of CD18 panleukocyte marker do not differ between patients and controls [296]. In patients with severe sepsis, inflammatory markers are increased in the external intercostals compared to controls [263].

Collectively, respiratory muscle dysfunction in patients with COPD is the result of multiple deleterious factors such as lung hyperinflation (mechanical disadvantage), gas exchange abnormalities, impaired bioenergetics (increased cost of breathing) and biological mechanisms (oxidative stress), and structural abnormalities (sarcomere damage and atrophy), while inflammation does not seem to play a major role [295]. This scenario coexists with adaptive features including a switch towards a more oxidative phenotype (predominance of slow-twitch fibres, increased mitochondrial density and myoglobin content), probably in response to increased mechanical loads.

\section{Conclusion}

Respiratory muscle dysfunction is a major clinical concern in a variety of conditions, from respiratory diseases to NMDs, critically ill patients, sports medicine and paediatric populations. Assessment of respiratory muscle function is therefore of critical importance for patient diagnosis, follow-up and for evaluating the effect of therapeutic interventions aimed at improving respiratory function. 17 years after the 2002 ATS/ERS statement on respiratory muscle testing [1], a growing body of literature has emerged and has been discussed in this document, which provides clinicians and investigators with the latest knowledge on this topic. In addition to historical evidence on respiratory muscle strength, endurance and fatigue assessments, new information on imaging technologies and respiratory muscle assessment during exercise have provided important insights into respiratory muscle function, including its integration with brain and cardiovascular function, dyspnoea and exercise tolerance. This document, which has involved experts in the field of respiratory medicine and physiology on the topic of respiratory muscle testing at rest and during exercise, is intended to open up new perspectives in both clinical and research settings. Despite the remarkable advances in respiratory muscle and lung mechanics assessment in the past few decades, this body of knowledge has not been fully translated to the clinical care of individual patients. Although this state of affairs is likely explained by multiple reasons, it is noteworthy that less and less time has been devoted to training in the administration and interpretation of the more advanced tests of respiratory muscle function worldwide. This contributes to a vicious circle in which fewer pulmonologists master the use of less common devices that are available only in specialised centres. To fight this regrettable situation, it seems apparent that new generations of pulmonologists should (again) be intensively exposed to clinical physiology concepts and practices. To reach this intent, the key relevance of the leading societies in our field (e.g. the European Respiratory Society, American Thoracic Society and American College of Chest Physicians) cannot be underestimated.

Conflict of interest: P. Laveneziana reports personal fees from Novartis France and Boehringer France, outside the submitted work. A. Albuquerque has nothing to disclose. A. Aliverti has a patent optoelectronic plethysmography licensed to BTS Bioengineering. T. Babb has nothing to disclose. E. Barreiro has nothing to disclose. M. Dres reports personal fees for research from Lungpacer, fees for conference accommodation from Pulsion Medical System and 
Maquet, outside the submitted work. B-P. Dubé reports grants and personal fees from Novartis and Roche, personal fees from Boehringer Ingelheim and GSK, outside the submitted work. B. Fauroux has nothing to disclose. J. Gea has nothing to disclose. J.A. Guenette has nothing to disclose. A.L. Hudson reports grants from Lung Foundation Australia and Boehringer Ingelheim, during the conduct of the study; grants from Rebecca L. Cooper Foundation, Lung Foundation Australia, Boehringer Ingelheim, National Health and Medical Research Council (Australia) and University of New South Wales, outside the submitted work. H-J. Kabitz reports personal fees and non-financial support from Inomed Medizintechnik $\mathrm{GmbH}$, non-financial support from nSpire Health $\mathrm{GmbH}$, during the conduct of the study. F. Laghi reports grants from National Institutes of Health, VA Research Service, Liberate Medical LLC and National Science Foundation, outside the submitted work. D. Langer has nothing to disclose. Y-M. Luo has nothing to disclose. J.A. Neder has nothing to disclose. D. O'Donnell reports grants and personal fees from AstraZeneca, Boehringer Ingelheim and GlaxoSmithKline, personal fees from Almirall, Novartis and Pfizer, outside the submitted work. M.I. Polkey reports personal and institutional payments for consultancy and speaking from Amicus, Genzyme Sanofi and Biomarin, institutional payments for consultancy from Orion, during the conduct of the study. R.A. Rabinovich has nothing to disclose. A. Rossi has nothing to disclose. F. Series has nothing to disclose. T. Similowski reports personal fees for advisory board work from Pierre Fabre Médicament, during the conduct of the study; personal fees from AstraZeneca, Boehringer Ingelheim France, GSK, Lungpacer Inc., TEVA, Chiesi and Invacare, personal fees and non-financial support from Novartis, outside the submitted work. C.M. Spengler has nothing to disclose. I. Vogiatzis has nothing to disclose. S. Verges has nothing to disclose.

\section{References}

1 American Thoracic Society/European Respiratory Society. ATS/ERS statement on respiratory muscle testing. Am J Respir Crit Care Med 2002; 166: 518-624.

2 Loring SH, Yoshino K, Kimball WR, et al. Gravitational and shear-associated pressure gradients in the abdomen. J Appl Physiol 1994; 77: 1375-1382.

3 Jackson AC, Vinegar A. A technique for measuring frequency response of pressure, volume, and flow transducers. J Appl Physiol Respir Environ Exerc Physiol 1979; 47: 462-467.

4 Milic-Emili J, Mead J, Turner JM, et al. Improved technique for estimating pleural pressure from esophageal balloons. J Appl Physiol 1964; 19: 207-211.

$5 \quad$ Walterspacher S, Isaak L, Guttmann J, et al. Assessing respiratory function depends on mechanical characteristics of balloon catheters. Respir Care 2014; 59: 1345-1352.

6 Augusto RM, Albuquerque AL, Jaeger T, et al. Stability and agreement of a microtransducer and an air-filled balloon esophageal catheter in the monitoring of esophageal pressure. Respir Care 2017; 62: 215-221.

7 Heritier F, Rahm F, Pasche P, et al. Sniff nasal inspiratory pressure. A noninvasive assessment of inspiratory muscle strength. Am J Respir Crit Care Med 1994; 150: 1678-1683.

Mead J. Mechanical properties of lungs. Physiol Rev 1961; 41: 281-330.

Killian KJ, Jones NL. Respiratory muscles and dyspnea. Clin Chest Med 1988; 9: 237-248.

10 Rodrigues A, Da Silva ML, Berton DC, et al. Maximal inspiratory pressure: does the choice of reference values actually matter? Chest 2017; 152: 32-39.

11 Sclauser Pessoa IM, Franco Parreira V, Fregonezi GA, et al. Reference values for maximal inspiratory pressure: a systematic review. Can Respir J 2014; 21: 43-50.

12 Maillard JO, Burdet L, van Melle G, et al. Reproducibility of twitch mouth pressure, sniff nasal inspiratory pressure, and maximal inspiratory pressure. Eur Respir J 1998; 11: 901-905.

13 Nikoletou D, Rafferty G, Man WD, et al. Sniff nasal inspiratory pressure in patients with moderate-to-severe chronic obstructive pulmonary disease: learning effect and short-term between-session repeatability. Respiration 2014; 88: 365-370.

14 Khirani S, Colella M, Caldarelli V, et al. Longitudinal course of lung function and respiratory muscle strength in spinal muscular atrophy type 2 and 3. Eur J Paediatr Neurol 2013; 17: 552-560.

15 King M, Brock G, Lundell C. Clearance of mucus by simulated cough. J Appl Physiol 1985; 58: 1776-1782.

16 Suarez AA, Pessolano FA, Monteiro SG, et al. Peak flow and peak cough flow in the evaluation of expiratory muscle weakness and bulbar impairment in patients with neuromuscular disease. Am J Phys Med Rehab 2002; 81: 506-511.

17 Sancho J, Servera E, Diaz J, et al. Comparison of peak cough flows measured by pneumotachograph and a portable peak flow meter. Am J Phys Med Rehab 2004; 83: 608-612.

18 Bach JR. Update and perspectives on noninvasive respiratory muscle aids 0.1. The inspiratory aids. Chest 1994; 105: 1230-1240.

19 Tzani P, Chiesa S, Aiello M, et al. The value of cough peak flow in the assessment of cough efficacy in neuromuscular patients. A cross sectional study. Eur J Phys Rehab Med 2014; 50: 427-432.

20 Steier J, Kaul S, Seymour J, et al. The value of multiple tests of respiratory muscle strength. Thorax 2007; 62: 975-980.

21 Man WDC, Kyroussis D, Fleming TA, et al. Cough gastric pressure and maximum expiratory mouth pressure in humans. Am J Respir Crit Care Med 2003; 168: 714-717.

22 Koulouris N, Mulvey DA, Laroche CM, et al. The measurement of inspiratory muscle strength by sniff esophageal, nasopharyngeal, and mouth pressures. Am Rev Respir Dis 1989; 139: 641-646.

23 Garcia-Rio F, Mediano O, Pino JM, et al. Noninvasive measurement of the maximum relaxation rate of inspiratory muscles in patients with neuromuscular disorders. Respiration 2006; 73: 474-480.

24 Luo YM, Hart N, Mustfa N, et al. Reproducibility of twitch and sniff transdiaphragmatic pressures. Respir Physiol Neurobiol 2002; 132: 301-306.

25 Mulvey DA, Elliott MW, Koulouris NG, et al. Sniff esophageal and nasopharyngeal pressures and maximal relaxation rates in patients with respiratory dysfunction. Am Rev Respir Dis 1991; 143: 950-953.

26 Evans SA, Watson L, Hawkins M, et al. Respiratory muscle strength in chronic heart failure. Thorax 1995; 50: 625-628.

27 Ward K, Seymour J, Steier J, et al. Acute ischaemic hemispheric stroke is associated with impairment of reflex in addition to voluntary cough. Eur Respir J 2010; 36: 1383-1390. 
Fauroux B, Aubertin G, Cohen E, et al. Sniff nasal inspiratory pressure in children with muscular, chest wall or lung disease. Eur Respir J 2009; 33: 113-117.

Aiello M, Rampello A, Granella F, et al. Cough efficacy is related to the disability status in patients with multiple sclerosis. Respiration 2008; 76: 311-316.

Nicot F, Hart N, Forin V, et al. Respiratory muscle testing: a valuable tool for children with neuromuscular disorders. Am J Respir Crit Care Med 2006; 174: 67-74.

Quijano-Roy S, Khirani S, Colella M, et al. Diaphragmatic dysfunction in collagen VI myopathies. Neuromuscul Disord 2014; 24: 125-133.

Morgan RK, McNally S, Alexander $\mathrm{M}$, et al. Use of sniff nasal-inspiratory force to predict survival in amyotrophic lateral sclerosis. Am J Respir Crit Care Med 2005; 171: 269-274.

Polkey MI, Lyall RA, Yang K, et al. Respiratory muscle strength as a predictive biomarker for survival in amyotrophic lateral sclerosis. Am J Respir Crit Care Med 2017; 195: 86-95.

Criner G, Cordova FC, Leyenson V, et al. Effect of lung volume reduction surgery on diaphragm strength. Am Respir Crit Care Med 1998; 157: 1578-1585.

Kyroussis D, Polkey MI, Keilty SE, et al. Exhaustive exercise slows inspiratory muscle relaxation rate in chronic obstructive pulmonary disease. Am J Respir Crit Care Med 1996; 153: 787-793.

De Troyer A, Borenstein S, Cordier R. Analysis of lung volume restriction in patients with respiratory muscle weakness. Thorax 1980; 35: 603-610.

Fallat RJ, Jewitt B, Bass M, et al. Spirometry in amyotrophic lateral sclerosis. Arch Neurol 1979; 36: 74-80.

Lechtzin N, Wiener CM, Shade DM, et al. Spirometry in the supine position improves the detection of diaphragmatic weakness in patients with amyotrophic lateral sclerosis. Chest 2002; 121: 436-442.

Varrato I, Siderowf A, Damiano P, et al. Postural change of forced vital capacity predicts some respiratory symptoms in ALS. Neurology 2001; 57: 357-359.

Lisboa C, Pare PD, Pertuze J, et al. Inspiratory muscle function in unilateral diaphragmatic paralysis. Am Rev Respir Dis 1986; 134: 488-492.

Laroche CM, Mier AK, Moxham J, et al. Diaphragm strength in patients with recent hemidiaphragm paralysis. Thorax 1988; 43: 170-174.

Leche CM, Carroll N, Moxham J, et al. Clinical significance of severe isolated diaphragm weakness. Am Rev Respir Dis 1988; 138: 862-866.

Mier-Jedrzejowicz A, Brophy C, Moxham J, et al. Assessment of diaphragm weakness. Am Rev Respir Dis 1988; 137: 877-883.

Stambler N, Charatan M, Cedarbaum JM. Prognostic indicators of survival in ALS. ALS CNTF Treatment Study Group. Neurology 1998; 50: 66-72.

Lacomblez L, Bensimon G, Leigh PN, et al. Dose-ranging study of riluzole in amyotrophic lateral sclerosis. Amyotrophic Lateral Sclerosis/Riluzole Study Group II. Lancet 1996; 347: 1425-1431.

Meininger V, Bensimon G, Bradley WR, et al. Efficacy and safety of xaliproden in amyotrophic lateral sclerosis: results of two phase III trials. Amyotroph Lateral Scler Other Motor Neuron Disord 2004; 5: 107-117.

Phillips MF, Quinlivan RC, Edwards RH, et al. Changes in spirometry over time as a prognostic marker in patients with Duchenne muscular dystrophy. Am J Respir Crit Care Med 2001; 164: 2191-2194.

Chevrolet JC, Deleamont P. Repeated vital capacity measurements as predictive parameters for mechanica ventilation need and weaning success in the Guillain-Barre syndrome. Am Rev Respir Dis 1991; 144: 814-818.

Bourke SC, Tomlinson M, Williams TL, et al. Effects of non-invasive ventilation on survival and quality of life in patients with amyotrophic lateral sclerosis: a randomised controlled trial. Lancet Neurol 2006; 5: 140-147.

Van der Beek NA, Hagemans ML, Reuser AJ, et al. Rate of disease progression during long-term follow-up of patients with late-onset Pompe disease. Neuromuscul Disord 2009; 19: 113-117.

Clinical indications for noninvasive positive pressure ventilation in chronic respiratory failure due to restrictive lung disease, COPD, and nocturnal hypoventilation - a consensus conference report. Chest 1999; 116: 521-534. Johnson EM, Roberts M, Mozaffar T, et al. Pulmonary function tests (maximum inspiratory pressure, maximum expiratory pressure, vital capacity, forced vital capacity) predict ventilator use in late-onset Pompe disease. Neuromuscul Disord 2016; 26: 136-145.

Ragette R, Mellies U, Schwake C, et al. Patterns and predictors of sleep disordered breathing in primary myopathies. Thorax 2002; 57: 724-728.

Akoumianaki E, Maggiore SM, Valenza F, et al. The application of esophageal pressure measurement in patients with respiratory failure. Am J Respir Crit Care Med 2014; 189: 520-531.

Kyroussis D, Mills GH, Polkey MI, et al. Abdominal muscle fatigue after maximal ventilation in humans. J Appl Physiol 1996; 81: 1477-1483.

Hamnegard $\mathrm{CH}$, Wragg S, Kyroussis D, et al. Diaphragm fatigue following maximal ventilation in man. Eur Respir J 1996; 9: 241-247.

Maltais F, Reissmann H, Gottfried SB. Pressure support reduces inspiratory effort and dyspnea during exercise in chronic airflow obstruction. Am J Respir Crit Care Med 1995; 151: 1027-1033.

CS, Lodia R, Light RW, et al. Maximum inspiratory muscle endurance capacity during resistive loading in chronic obstructive pulmonary disease. Respiration 1990; 57: 343-350.

Polkey MI, Kyroussis D, Hamnegard CH, et al. Diaphragm performance during maximal voluntary ventilation in chronic obstructive pulmonary disease. Am J Respir Crit Care Med 1997; 155: 642-648.

Field S, Sanci S, Grassino A. Respiratory muscle oxygen consumption estimated by the diaphragm pressure-time index. J Appl Physiol Respir Environ Exerc Physiol 1984; 57: 44-51.

Jubran A, Tobin MJ. Pathophysiologic basis of acute respiratory distress in patients who fail a trial of weaning from mechanical ventilation. Am J Respir Crit Care Med 1997; 155: 906-915.

Laveneziana $\mathrm{P}$, Webb KA, Wadell K, et al. Does expiratory muscle activity influence dynamic hyperinflation and exertional dyspnea in COPD? Respir Physiol Neurobiol 2014; 199: 24-33.

Duranti R, Bonetti L, Vivoli P, et al. Dyspnea during exercise in hyperbaric conditions. Med Sci Sports Exerc 2006; 38: 1932-1938.

Faisal A, Alghamdi BJ, Ciavaglia CE et al Common mechanisms of dyspnea in chronic interstitial and obstructive lung disorders. Am J Respir Crit Care Med 2016; 193: 299-309. 
O’Donnell DE, Laveneziana P, Webb K, et al. Chronic obstructive pulmonary disease: clinical integrative physiology. Clin Chest Med 2014; 35: 51-69.

66 Laveneziana P, Webb KA, Ora J, et al. Evolution of dyspnea during exercise in chronic obstructive pulmonary disease: impact of critical volume constraints. Am J Respir Crit Care Med 2011; 184: 1367-1373.

67 Kushida CA. The use of esophageal manometry in the diagnosis of sleep-related breathing disorders. Conf Proc IEEE Eng Med Biol Soc 2004; 5: 3860-3863.

68 Jubran A, Grant BJ, Laghi F, et al. Weaning prediction: esophageal pressure monitoring complements readiness testing. Am J Respir Crit Care Med 2005; 171: 1252-1259.

69 Petrof BJ, Calderini E, Gottfried SB. Effect of CPAP on respiratory effort and dyspnea during exercise in severe COPD. J Appl Physiol 1990; 69: 179-188.

70 Eves ND, Petersen SR, Haykowsky MJ, et al. Helium-hyperoxia, exercise, and respiratory mechanics in chronic obstructive pulmonary disease. Am J Respir Crit Care Med 2006; 174: 763-771.

71 Hatipoglu U, Laghi F, Tobin M. Does inhaled albuterol improve diaphragmatic contractility in patients with chronic obstructive pulmonary disease? Am J Respir Crit Care Med 1999; 160: 1916-1921.

72 Man WD, Mustfa N, Nikoletou D, et al. Effect of salmeterol on respiratory muscle activity during exercise in poorly reversible COPD. Thorax 2004; 59: 471-476.

73 O'Donnell DE, Hamilton AL, Webb K. Sensory-mechanical relationships during high-intensity, constant-work-rate exercise in COPD. J Appl Physiol 2006; 101: 1025-1035.

74 Collins EG, Langbein WE, Fehr L, et al. Can ventilation-feedback training augment exercise tolerance in patients with chronic obstructive pulmonary disease? Am J Respir Crit Care Med 2008; 177: 844-852. Macklem PT. Therapeutic implications of the pathophysiology of COPD. Eur Respir J 2010; 35: 676-680.

76 Spahija J, de Marchie M, Grassino A. Effects of imposed pursed-lips breathing on respiratory mechanics and dyspnea at rest and during exercise in COPD. Chest 2005; 128: 640-650. Breslin EH. The pattern of respiratory muscle recruitment during pursed-lip breathing. Chest 1992; 101: 75-78.

78 Hughes PD, Polkey MI, Kyroussis D, et al. Measurement of sniff nasal and diaphragm twitch mouth pressure in patients. Thorax 1998; 53: 96-100.

79 Luo YM, Hart N, Mustfa N, et al. Reproducibility of twitch and sniff transdiaphragmatic pressures. Respir Physiolo Neurobiol 2002; 132: 301-306.

80 Laghi F, Cattapan SE, Jubran A, et al. Is weaning failure caused by low-frequency fatigue of the diaphragm? Am J Respir Crit Care Med 2003; 167: 120-127.

81 Rafferty GF, Greenough A, Dimitriou G, et al. Assessment of neonatal diaphragm function using magnetic stimulation of the phrenic nerves. Am J Respir Crit Care Med 2000; 162: 2337-2340.

82 Dimitriou G, Greenough A, Moxham J, et al. Influence of maturation on infant diaphragm function assessed by magnetic stimulation of phrenic nerves. Pediatr Pulmonol 2003; 35: 17-22.

83 Rafferty GF, Mustfa N, Man WD, et al. Twitch airway pressure elicited by magnetic phrenic nerve stimulation in anesthetized healthy children. Pediatr Pulmonol 2005; 40: 141-147.

84 Supinski GS, Callahan LA. Diaphragm weakness in mechanically ventilated critically ill patients. Crit Care 2013; 17: R120.

85 Mills GH, Ponte J, Hamnegard $\mathrm{CH}$, et al. Tracheal tube pressure change during magnetic stimulation of the phrenic nerves as an indicator of diaphragm strength on the intensive care unit. Br J Anaesth 2001; 87: 876-884.

86 Langer D, Jacome C, Charususin N, et al. Measurement validity of an electronic inspiratory loading device during a loaded breathing task in patients with COPD. Respir Med 2013; 107: 633-635.

87 Wuthrich TU, Marty J, Benaglia P, et al. Acute effects of a respiratory sprint-interval session on muscle contractility. Med Sci Sports Exerc 2015; 47: 1979-1987.

88 Hart N, Hawkins P, Hamnegard $\mathrm{CH}$, et al. A novel clinical test of respiratory muscle endurance. Eur Respir J 2002; 19: 232-239.

89 Hill K, Jenkins SC, Philippe DL, et al. Comparison of incremental and constant load tests of inspiratory muscle endurance in COPD. Eur Respir J 2007; 30: 479-486.

90 Vincent M, Court-Fortune I, Brun C, et al. Determination of normal values for an isocapnic hyperpnea endurance test in healthy individuals. Respir Physiol Neurobiol 2016; 230: 5-10.

91 Mancini DM, Henson D, La Manca J, et al. Benefit of selective respiratory muscle training on exercise capacity in patients with chronic congestive heart failure. Circulation 1995; 91: 320-329.

92 Mancini DM, Henson D, LaManca J, et al. Evidence of reduced respiratory muscle endurance in patients with heart failure. J Am Coll Cardiol 1994; 24: 972-981.

93 Butler JE. Drive to the human respiratory muscles. Respir Physiol Neurobiol 2007; 159: 115-126.

94 Luo YM, Moxham J, Polkey MI. Diaphragm electromyography using an oesophageal catheter: current concepts. Clin Sci 2008; 115: 233-244.

95 Laghi F, Staikh HS, Morales D, et al. Diaphragmatic neuromechanical coupling and mechanisms of hypercapnia during inspiratory loading. Respir Physiol Neurobiol 2014; 1: 32-41.

96 Qin YY, Steier J, Jolley C, et al. Efficiency of neural drive during exercise in patients with COPD and healthy subjects. Chest 2010; 138: 1309-1315.

97 Jolley CJ, Luo YM, Steier J, et al. Neural respiratory drive and breathlessness in COPD. Eur Respir J 2015; 45: 355-364.

98 Schweitzer TW, Fitzgerald JW, Bowden JA, et al. Spectral analysis of human inspiratory diaphragmatic electromyograms. J Appl Physiol Respir Environ Exerc Physiol 1979; 46: 152-165.

99 Bartolo A, Roberts C, Dzwonczyk RR, et al. Analysis of diaphragm EMG signals: comparison of gating vs. subtraction for removal of ECG contamination. J Appl Physiol 1996; 80: 1898-1902.

100 Schmidt M, Chiti L, Hug F, et al. Surface electromyogram of inspiratory muscles: a possible routine monitoring tool in the intensive care unit. Br J Anaesth 2011; 106: 913-914.

101 Gandevia SC, McKenzie DK. Human diaphragmatic EMG: changes with lung volume and posture during supramaximal phrenic stimulation. J Appl Physiol 1986; 60: 1420-1428.

102 Luo YM, Lyall RA, Lou Harris M, et al. Quantification of the esophageal diaphragm electromyogram with magnetic phrenic nerve stimulation. Am J Respir Crit Care Med 1999; 160: 1629-1634. 
103 Jolley CJ, Luo YM, Steier J, et al. Neural respiratory drive in healthy subjects and in COPD. Eur Respir J 2009; 33: 289-297.

104 Reilly CC, Jolley CJ, Ward K, et al. Neural respiratory drive measured during inspiratory threshold loading and acute hypercapnia in healthy individuals. Exp Physiol 2013; 98: 1190-1198.

105 Murphy PB, Kumar A, Reilly C, et al. Neural respiratory drive as a physiological biomarker to monitor change during acute exacerbations of COPD. Thorax 2011; 66: 602-608.

106 MacBean V, Hughes C, Nicol G, et al. Measurement of neural respiratory drive via parasternal intercostal electromyography in healthy adult subjects. Physiol Meas 2016; 37: 2050-2063.

107 Suh ES, Mandal S, Harding R, et al. Neural respiratory drive predicts clinical deterioration and safe discharge in exacerbations of COPD. Thorax 2015; 70: 1123-1130.

108 Ramsook AH, Mitchell RA, Bell T, et al. Is parasternal intercostal EMG an accurate surrogate of respiratory neural drive and biomarker of dyspnea during cycle exercise testing? Respir Physiol Neurobiol 2017; 242: $40-44$.

109 Similowski T, Mehiri S, Duguet A, et al. Comparison of magnetic and electrical phrenic nerve stimulation in assessment of phrenic nerve conduction time. J Appl Physiol 1997; 82: 1190-1199.

110 Luo YM, Polkey MI, Lyall RA, et al. Effect of brachial plexus co-activation on phrenic nerve conduction time. Thorax 1999; 54: 765-770.

111 Berry RB, Ryals S, Girdhar A, et al. Use of chest wall electromyography to detect respiratory effort during polysomnography. J Clin Sleep Med 2016; 12: 1239-1244.

112 Luo YM, Tang J, Jolley C, et al. Distinguishing obstructive from central sleep apnea events: diaphragm electromyogram and esophageal pressure compared. Chest 2009; 135: 1133-1141.

113 Stoohs RA, Blum HC, Knaack L, et al. Comparison of pleural pressure and transcutaneous diaphragmatic electromyogram in obstructive sleep apnea syndrome. Sleep 2005; 28: 321-329.

114 Luo YM, He BT, Wu YX, et al. Neural respiratory drive and ventilation in patients with chronic obstructive pulmonary disease during sleep. Am J Respir Crit Care Med 2014; 190: 227-229.

115 Elbehairy AF, Guenette JA, Faisal A, et al. Mechanisms of exertional dyspnoea in symptomatic smokers without COPD. Eur Respir J 2016; 48: 694-705.

116 Ciavaglia CE, Guenette JA, Langer D, et al. Differences in respiratory muscle activity during cycling and walking do not influence dyspnea perception in obese patients with COPD. J Appl Physiol 2014; 117: 1292-1301.

117 He BT, Lu G, Xiao SC, et al. Coexistence of OSA may compensate for sleep related reduction in neura respiratory drive in patients with COPD. Thorax 2017; 72: 256-262

118 De Troyer A, Leeper JB, McKenzie DK, et al. Neural drive to the diaphragm in patients with severe COPD. Am J Respir Crit Care Med 1997; 155: 1335-1340.

119 Gandevia SC, Leeper JB, McKenzie DK, et al. Discharge frequencies of parasternal intercostal and scalene motor units during breathing in normal and COPD subjects. Am J Respir Crit Care Med 1996; 153: 622-628.

120 Qin YY, Li RF, Wu GF, et al. Effect of tiotropium on neural respiratory drive during exercise in severe COPD. Pulm Pharmacol Ther 2015; 30: 51-56.

121 Yokoba M, Ichikawa T, Takakura A, et al. Aminophylline increases respiratory muscle activity during hypercapnia in humans. Pulm Pharmacol Ther 2015; 30: 96-101.

122 Gorman RB, McKenzie DK, Butler JE, et al. Diaphragm length and neural drive after lung volume reduction surgery. Am J Respir Crit Care Med 2005; 172: 1259-1266.

123 Firestone KS, Beck J, Stein H. Neurally adjusted ventilatory assist for noninvasive support in neonates. Clin Perinatol 2016; 43: 707-724.

124 Doorduin J, Sinderby CA, Beck J, et al. Assisted ventilation in patients with acute respiratory distress syndrome: lung-distending pressure and patient-ventilator interaction. Anesthesiology 2015; 123: 181-190.

125 Sinderby C, Navalesi P, Beck J, et al. Neural control of mechanical ventilation in respiratory failure. Nat Med 1999; 5: 1433-1436.

126 Bellani G, Mauri T, Coppadoro A, et al. Estimation of patient's inspiratory effort from the electrical activity of the diaphragm. Crit Care Med 2013; 41: 1483-1491.

127 Dres M, Schmidt M, Ferre A, et al. Diaphragm electromyographic activity as a predictor of weaning failure. Intensive Care Med 2012; 38: 2017-2025.

128 Raux M, Straus C, Redolfi S, et al. Electroencephalographic evidence for pre-motor cortex activation during inspiratory loading in humans. J Physiol (Lond) 2007; 578: 569-578.

129 Jutand L, Tremoureux L, Pichon A, et al. Ventilatory response to exercise does not evidence electroencephalographical respiratory-related activation of the cortical premotor circuitry in healthy humans. Acta Physiol 2012; 205: 356-362.

130 McKay LC, Adams L, Frackowiak RS, et al. A bilateral cortico-bulbar network associated with breath holding in humans, determined by functional magnetic resonance imaging. Neuroimage 2008; 40: 1824-1832.

131 Hudson AL, Navarro-Sune X, Martinerie J, et al. Electroencephalographic detection of respiratory-related cortical activity in humans: from event-related approaches to continuous connectivity evaluation. J Neurophysiol 2016; 115: 2214-2223.

132 Tremoureux L, Raux M, Ranohavimparany A, et al. Electroencephalographic evidence for a respiratory-related cortical activity specific of the preparation of prephonatory breaths. Respir Physiol Neurobiol 2014; 204: 64-70.

133 Laviolette L, Nierat MC, Hudson AL, et al. The supplementary motor area exerts a tonic excitatory influence on corticospinal projections to phrenic motoneurons in awake humans. PLoS One 2013; 8: e62258.

134 Dubois M, Chenivesse C, Raux M, et al. Neurophysiological evidence for a cortical contribution to the wakefulness-related drive to breathe explaining hypocapnia-resistant ventilation in humans. J Neurosci 2016; 36: 10673-10682.

135 Tremoureux L, Raux M, Jutand L, et al. Sustained preinspiratory cortical potentials during prolonged inspiratory threshold loading in humans. J Appl Physiol 2010; 108: 1127-1133.

136 Raux M, Tyvaert L, Ferreira M, et al. Functional magnetic resonance imaging suggests automatization of the cortical response to inspiratory threshold loading in humans. Respir Physiol Neurobiol 2013; 189: 571-580.

137 Raux M, Ray P, Prella M, et al. Cerebral cortex activation during experimentally induced ventilator fighting in normal humans receiving noninvasive mechanical ventilation. Anesthesiology 2007; 107: 746-755. 
138 Morawiec E, Raux M, Kindler F, et al. Expiratory load compensation is associated with electroencephalographic premotor potentials in humans. J Appl Physiol 2015; 118: 1023-1030.

139 Tremoureux L, Raux M, Hudson AL, et al. Does the supplementary motor area keep patients with Ondine's curse syndrome breathing while awake? PLoS One 2014; 9: e84534.

140 Sharman M, Gallea C, Lehongre K, et al. The cerebral cost of breathing: an FMRI case-study in congenital central hypoventilation syndrome. PloS one 2014; 9: e107850.

141 Nierat MC, Demiri S, Dupuis-Lozeron E, et al. When breathing interferes with cognition: experimental inspiratory loading alters timed up-and-go test in normal humans. PLoS One 2016; 11: e0151625.

142 Launois C, Attali V, Georges M, et al. Cortical drive to breathe during wakefulness in patients with obstructive sleep apnea syndrome. Sleep 2015; 38: 1743-1749.

143 Georges $\mathrm{M}$, Morawiec E, Raux M, et al. Cortical drive to breathe in amyotrophic lateral sclerosis: a dyspnoea-worsening defence? Eur Respir J 2016; 47: 1818-1828.

144 Navarro-Sune X, Hudson AL, De Vico Fallani F, et al. Riemannian geometry applied to detection of respiratory states from EEG signals: the basis for a brain-ventilator interface. IEEE Trans Biomed Eng 2017; 64: 1138-1148.

145 Hallett M. Transcranial magnetic stimulation and the human brain. Nature 2000; 406: 147-150.

146 Anand S, Hotson J. Transcranial magnetic stimulation: neurophysiological applications and safety. Brain Cogn 2002; 50: 366-386.

147 Keel JC, Smith MJ, Wassermann EM. A safety screening questionnaire for transcranial magnetic stimulation. Clin Neurophysiol 2001; 112: 720.

148 Demoule A, Verin E, Locher C, et al. Validation of surface recordings of the diaphragm response to transcranial magnetic stimulation in humans. J Appl Physiol 2003; 94: 453-461.

149 Straus C, Locher C, Zelter M, et al. Facilitation of the diaphragm response to transcranial magnetic stimulation by increases in human respiratory drive. J Appl Physiol 2004; 97: 902-912.

150 Mehiri S, Straus C, Arnulf I, et al. Responses of the diaphragm to transcranial magnetic stimulation during wake and sleep in humans. Respir Physiol Neurobiol 2006; 154: 406-418.

151 Demoule A, Verin E, Ross E, et al. Intracortical inhibition and facilitation of the response of the diaphragm to transcranial magnetic stimulation. J Clin Neurophysiol 2003; 20: 59-64.

152 Similowski T, Straus C, Coic L, et al. Facilitation-independent response of the diaphragm to cortical magnetic stimulation. Am J Respir Crit Care Med 1996; 154: 1771-1777.

153 Lagueny A, Arnaud A, Le Masson G, et al. Study of central and peripheral conductions to the diaphragm in 22 patients with definite multiple sclerosis. Electromyogr Clin Neurophysiol 1998; 38: 333-342.

154 Similowski T, Attali V, Bensimon G, et al. Diaphragmatic dysfunction and dyspnoea in amyotrophic lateral sclerosis. Eur Respir J 2000; 15: 332-337.

155 Wang W, Kang J, Kong D. The central motor conductivity of genioglossus in obstructive sleep apnoea. Respirology 2010; 15: 1209-1214.

156 Series F, Wang W, Similowski T. Corticomotor control of the genioglossus in awake OSAS patients: a transcranial magnetic stimulation study. Respir Res 2009; 10: 74

157 Melo-Silva CA, Borel JC, Gakwaya S, et al. Acute upper airway muscle and inspiratory flow responses to transcranial magnetic stimulation during sleep in apnoeic patients. Exp Physiol 2013; 98: 946-956.

158 Melo-Silva CA, Gakwaya S, Rousseau E, et al. Consecutive transcranial magnetic stimulation twitches reduce flow limitation during sleep in apnoeic patients. Exp Physiol 2013; 98: 1366-1375.

159 Rousseau E, Gakwaya S, Melo-Silva CA, et al. Mechanical effects of repetitive transcranial magnetic stimulation of upper airway muscles in awake obstructive sleep apnoea subjects. Exp Physiol 2015; 100: 566-576.

160 Rousseau E, Melo-Silva CA, Gakwaya S, et al. Effects of repetitive transcranial magnetic stimulation of upper airway muscles during sleep in obstructive sleep apnea patients. J Appl Physiol 2016; 121: 1217-1225.

161 Hopkinson NS, Sharshar T, Dayer MJ, et al. The effect of acute non-invasive ventilation on corticospinal pathways to the respiratory muscles in chronic obstructive pulmonary disease. Respir Physiol Neurobiol 2012; 183: $41-47$.

162 Hopkinson NS, Sharshar T, Ross ET, et al. Corticospinal control of respiratory muscles in chronic obstructive pulmonary disease. Respir Physiol Neurobiol 2004; 141: 1-12.

163 Duguet A, Demoule A, Gonzalez J, et al. Predicting the recovery of ventilatory activity in central respiratory paralysis. Neurology 2006; 67: 288-292.

164 Harraf F, Ward K, Man W, et al. Transcranial magnetic stimulation study of expiratory muscle weakness in acute ischemic stroke. Neurology 2008; 71: 2000-2007.

165 Houston JG, Fleet M, Cowan MD, et al. Comparison of ultrasound with fluoroscopy in the assessment of suspected hemidiaphragmatic movement abnormality. Clin Radiol 1995; 50: 95-98.

166 Matamis D, Soilemezi E, Tsagourias M, et al. Sonographic evaluation of the diaphragm in critically ill patients. Technique and clinical applications. Intensive Care Med 2013; 39: 801-810.

167 Boon AJ, Harper CJ, Ghahfarokhi LS, et al. Two-dimensional ultrasound imaging of the diaphragm: quantitative values in normal subjects. Muscle Nerve 2013; 47: 884-889.

168 Wait JL, Nahormek PA, Yost WT, et al. Diaphragmatic thickness-lung volume relationship in vivo. J Appl Physiol 1989; 67: 1560-1568.

169 Baldwin CE, Paratz JD, Bersten AD. Diaphragm and peripheral muscle thickness on ultrasound: intra-rater reliability and variability of a methodology using non-standard recumbent positions. Respirology 2011; 16: 1136-1143.

170 Cohn D, Benditt JO, Eveloff S, et al. Diaphragm thickening during inspiration. J Appl Physiol 1997; 83: 291-296.

171 Enright S, Chatham K, Ionescu AA, et al. The influence of body composition on respiratory muscle, lung function and diaphragm thickness in adults with cystic fibrosis. J Cyst Fibros 2007; 6: 384-390.

172 Baria MR, Shahgholi L, Sorenson EJ, et al. B-mode ultrasound assessment of diaphragm structure and function in patients with COPD. Chest 2014; 146: 680-685.

173 Hellyer NJ, Andreas NM, Bernstetter AS, et al. Comparison of diaphragm thickness measurements among postures via ultrasound imaging. PM R 2017; 9: 21-25.

174 McCool FD, Benditt JO, Conomos P, et al. Variability of diaphragm structure among healthy individuals. Am J Respir Crit Care Med 1997; 155: 1323-1328. 
Dufresne V, Knoop C, Van Muylem A, et al. Effect of systemic inflammation on inspiratory and limb muscle strength and bulk in cystic fibrosis. Am J Respir Crit Care Med 2009; 180: 153-158.

Summerhill EM, El-Sameed YA, Glidden TJ, et al. Monitoring recovery from diaphragm paralysis with ultrasound. Chest 2008; 133: 737-743.

Gottesman E, McCool FD. Ultrasound evaluation of the paralyzed diaphragm. Am J Respir Crit Care Med 1997; 155: $1570-1574$.

Bruin PFD, Ueki J, Bush A, et al. Diaphragm thickness and inspiratory strength in patients with Duchenne muscular dystrophy. Thorax 1997; 52: 474-475.

Goligher EC, Laghi F, Detsky ME, et al. Measuring diaphragm thickness with ultrasound in mechanically ventilated patients: feasibility, reproducibility and validity. Intensive Care Med 2015; 41: 642-649.

Vivier E, Dessap AM, Dimassi S, et al. Diaphragm ultrasonography to estimate the work of breathing during non-invasive ventilation. Intensive Care Med 2012; 38: 796-803.

Dube BP, Dres M. Mayaux J, et al. Ultrasound evaluation of diaphragm function in mechanically ventilated patients: comparison to phrenic stimulation and prognostic implications. Thorax 2017; 72: 811-818.

DiNino E, Gartman EJ, Sethi JM, et al. Diaphragm ultrasound as a predictor of successful extubation from mechanical ventilation. Thorax 2014; 69: 423-427.

Ferrari G, De Filippi G, Elia F, et al. Diaphragm ultrasound as a new index of discontinuation from mechanical ventilation. Crit Ultrasound J 2014; 6: 8.

Dube BP, Dres M, Mayaux J, et al. Ultrasound evaluation of diaphragm function in mechanically ventilated patients: comparison to phrenic stimulation and prognostic implications. Thorax 2017; 72: 811-818.

Goligher EC, Fan E, Herridge MS, et al. Evolution of diaphragm thickness during mechanical ventilation: impact of inspiratory effort. Am J Respir Crit Care Med 2015; 192: 1080-1088.

Grosu HB, Lee YI, Lee J, et al. Diaphragm muscle thinning in patients who are mechanically ventilated. Chest 2012; 142: 1455-1460.

Goligher EC, Laghi F, Detsky ME, et al. Measuring diaphragm thickness with ultrasound in mechanically ventilated patients: feasibility, reproducibility and validity. Intensive Care Med 2015; 41: 642-649.

Umbrello M, Formenti P, Longhi D, et al. Diaphragm ultrasound as indicator of respiratory effort in critically ill patients undergoing assisted mechanical ventilation: a pilot clinical study. Crit Care 2015; 19: 161.

Dres M, Dube BP, Mayaux J, et al. Coexistence and impact of limb muscle and diaphragm weakness at time of liberation from mechanical ventilation in medical intensive care unit patients. Am J Respir Crit Care Med 2017; 195: 57-66.

Antenora F, Fantini R, Iattoni A, et al. Prevalence and outcomes of diaphragmatic dysfunction assessed by ultrasound technology during acute exacerbation of COPD: a pilot study. Respirology 2017; 22: 338-344.

Boussuges A, Gole Y, Blanc P. Diaphragmatic motion studied by M-mode ultrasonography: methods, reproducibility, and normal values. Chest 2009; 135: 391-400.

Kim WY, Suh HJ, Hong SB, et al. Diaphragm dysfunction assessed by ultrasonography: influence on weaning from mechanical ventilation. Crit Care Med 2011; 39: 2627-2630.

Orde SR, Boon AJ, Firth DG, et al. Use of angle-independent M-mode sonography for assessment of diaphragm displacement. J Ultrasound Med 2016; 35: 2615-2621.

Jones AYMP, Ngai SPCP, Ying MTCP, et al. Sonographic evaluation of diaphragmatic function during breathing control. Physiother Theory Pract 2017; 33: 560-567.

Kim SH, Na S, Choi JS, et al. An evaluation of diaphragmatic movement by M-mode sonography as a predictor of pulmonary dysfunction after upper abdominal surgery. Anesth Analg 2010; 110: 1349-1354.

Numis FG, Morelli L, Bosso G, et al. Diaphragmatic motility assessment in COPD exacerbation, early detection of non-invasive mechanical ventilation failure: a pilot study. Crit Ultrasound J 2014; 6: Suppl. 2, A6.

Houston JG, Morris AD, Grosset DG, et al. Ultrasonic evaluation of movement of the diaphragm after acute cerebral infarction. J Neurol Neurosurg Psychiatry 1995; 58: 738-741.

Lerolle N, Guerot E, Dimassi S, et al. Ultrasonographic diagnostic criterion for severe diaphragmatic dysfunction after cardiac surgery. Chest 2009; 135: 401-407.

Spadaro S, Grasso S, Mauri T, et al. Can diaphragmatic ultrasonography performed during the T-tube trial predict weaning failure? The role of diaphragmatic rapid shallow breathing index. Crit Care 2016; 20: 305.

Trinavarat P, Riccabona M. Potential of ultrasound in the pediatric chest. Eur J Radiol 2014; 83: 1507-1518.

Cala SJ, Kenyon CM, Ferrigno G, et al. Chest wall and lung volume estimation by optical reflectance motion analysis. J Appl Physiol 1996; 81: 2680-2689.

Aliverti A, Dellaca R, Pelosi P, et al. Compartmental analysis of breathing in the supine and prone positions by optoelectronic plethysmography. Ann Biomed Eng 2001; 29: 60-70.

Vogiatzis I, Georgiadou O, Golemati S, et al. Patterns of dynamic hyperinflation during exercise and recovery in patients with severe chronic obstructive pulmonary disease. Thorax 2005; 60: 723-729.

Aliverti A, Stevenson N, Dellaca RL, et al. Regional chest wall volumes during exercise in chronic obstructive pulmonary disease. Thorax 2004; 59: 210-216.

Georgiadou O, Vogiatzis I, Stratakos G, et al. Effects of rehabilitation on chest wall volume regulation during exercise in COPD patients. Eur Respir J 2007; 29: 284-291.

Wilkens $\mathrm{H}$, Weingard B, Lo Mauro A, et al. Breathing pattern and chest wall volumes during exercise in patients with cystic fibrosis, pulmonary fibrosis and COPD before and after lung transplantation. Thorax 2010; 65: 808-814.

Mauro A L, D'Angelo MG, Romei M, et al. Abdominal volume contribution to tidal volume as an early indicator of respiratory impairment in Duchenne muscular dystrophy. Eur Respir J 2010; 35: 1118-1125.

LoMauro A, Romei M, D’Angelo MG, et al. Determinants of cough efficiency in Duchenne muscular dystrophy. Pediatr Pulmonol 2014; 49: 357-365.

Romei M, D'Angelo MG, LoMauro A, et al. Low abdominal contribution to breathing as daytime predictor of nocturnal desaturation in adolescents and young adults with Duchenne muscular dystrophy. Respir Med 2012; 106: $276-283$

D'Angelo MG, Romei M, Lo Mauro A, et al. Respiratory pattern in an adult population of dystrophic patients. J Neurol Sci 2011; 306: 54-61. 
211 Layton AM, Moran SL, Roychoudhury A, et al. Non-invasive measurement of abnormal ventilatory mechanics in amyotrophic lateral sclerosis. Muscle Nerve 2016; 54: 270-276.

212 Lunardi AC, Paisani Dde M, Tanaka C, et al. Impact of laparoscopic surgery on thoracoabdominal mechanics and inspiratory muscular activity. Respir Physiol Neurobiol 2013; 186: 40-44.

213 Acosta J, Bradley A, Raja V, et al. Exercise improvement after pectus excavatum repair is not related to chest wall function. Eur J Cardiothorac Surg 2014; 45: 544-548.

214 Elshafie G, Acosta J, Aliverti A, et al. Chest wall mechanics before and after diaphragm plication. J Cardiothorac Surg 2016; 11: 25 .

215 Laviola M, Zanini A, Priori R, et al. Thoraco-abdominal asymmetry and asynchrony in congenital diaphragmatic hernia. Pediatr Pulmonol 2015; 50: 915-924.

216 Sarmento A, de Andrade AF, Lima IN, et al. Air stacking: a detailed look into physiological acute effects on cough peak flow and chest wall volumes of healthy subjects. Respir Care 2017; 62: 432-443.

217 Jde M B, Aliverti A, Rattes C, et al. The expansion of the pulmonary rib cage during breath stacking is influenced by age in obese women. PLoS One 2014; 9: e110959.

218 de Sa RB, Pessoa MF, Cavalcanti AGL, et al. Immediate effects of respiratory muscle stretching on chest wall kinematics and electromyography in COPD patients. Respir Physiol Neurobiol 2017; 242: 1-7.

219 Paisani DM, Lunardi AC, da Silva CC, et al. Volume rather than flow incentive spirometry is effective in improving chest wall expansion and abdominal displacement using optoelectronic plethysmography. Respir Care 2013; 58: 1360-1366.

220 Brandao DC, Lage SM, Britto RR, et al. Chest wall regional volume in heart failure patients during inspiratory loaded breathing. Respir Physiol Neurobiol 2012; 180: 269-274.

221 Albuquerque AL, Quaranta M, Chakrabarti B, et al. Exercise performance and differences in physiological response to pulmonary rehabilitation in severe chronic obstructive pulmonary disease with hyperinflation. J Bras Pneumol 2016; 42: 121-129.

222 Dellaca RL, Ventura ML, Zannin E, et al. Measurement of total and compartmental lung volume changes in newborns by optoelectronic plethysmography. Pediatr Res 2010; 67: 11-16.

223 LoMauro A, Aliverti A, Mastella C, et al. Spontaneous breathing pattern as respiratory functional outcome in children with spinal muscular atrophy (SMA). PloS One 2016; 11: e0165818.

224 Harlaar L, Ciet P, van der Ploeg A, et al. Imaging of respiratory muscles in neuromuscular disease: a review. Neuromuscul Disord 2018; 28: 246-256.

225 Mogalle K, Perez-Rovira A, Ciet P, et al. Quantification of diaphragm mechanics in Pompe disease using dynamic 3D MRI. PloS One 2016; 11: e0158912.

226 Nierat MC, Dube BP, Llontop C, et al. Measuring ventilatory activity with structured light plethysmography (SLP) reduces instrumental observer effect and preserves tidal breathing variability in healthy and COPD. Front Physiol 2017; 8: 316.

227 Motamedi-Fakhr S, Iles R, Barney A, et al. Evaluation of the agreement of tidal breathing parameters measured simultaneously using pneumotachography and structured light plethysmography. Physiol Rep 2017; 5: e13124.

Motamedi-Fakhr S, Wilson RC, Iles R. Tidal breathing patterns derived from structured light plethysmography in COPD patients compared with healthy subjects. Med Devices (Auckl) 2017; 10: 1-9.

229 Elshafie G, Kumar P, Motamedi-Fakhr S, et al. Measuring changes in chest wall motion after lung resection using structured light plethysmography: a feasibility study. Interact Cardiovasc Thorac Surg 2016; 23: 544-547.

230 Hmeidi H, Motamedi-Fakhr S, Chadwick E, et al. Tidal breathing parameters measured using structured light plethysmography in healthy children and those with asthma before and after bronchodilator. Physiol Rep 2017; 5: e13168.

231 Guenette JA, Vogiatzis I, Zakynthinos S, et al. Human respiratory muscle blood flow measured by near-infrared spectroscopy and indocyanine green. J Appl Physiol 2008; 104: 1202-1210.

232 Vogiatzis I, Athanasopoulos D, Habazettl H, et al. Intercostal muscle blood flow limitation in athletes during maximal exercise. J Physiol 2009; 587: 3665-3677.

233 Vogiatzis I, Athanasopoulos D, Habazettl $\mathrm{H}$, et al. Intercostal muscle blood flow limitation during exercise in chronic obstructive pulmonary disease. Am J Respir Crit Care Med 2010; 182: 1105-1113.

234 Habazettl H, Athanasopoulos D, Kuebler WM, et al. Near-infrared spectroscopy and indocyanine green derived blood flow index for noninvasive measurement of muscle perfusion during exercise. J Appl Physiol 2010; 108: 962-967.

235 Guenette JA, Henderson WR, Dominelli PB, et al. Blood flow index using near-infrared spectroscopy and indocyanine green as a minimally invasive tool to assess respiratory muscle blood flow in humans. Am J Physiol Regul Integr Comp Physiol 2011; 300: R984-R992.

236 Dominelli PB, Render JN, Molgat-Seon Y, et al. Oxygen cost of exercise hyperpnoea is greater in women compared with men. J Physiol 2015; 593: 1965-1979.

237 Topin N, Mucci P, Hayot M, et al. Gender influence on the oxygen consumption on the respiratory muscles in young and older healthy individuals. Int J Sports Med 2003; 24: 559-564.

238 Kress JP, Pohlman AS, Alverdy J, et al. The impact of morbid obesity on oxygen cost of breathing $\left(\mathrm{VO}_{2 \mathrm{RESP}}\right)$ at rest. Am J Respir Crit Care Med 1999; 160: 883-886.

239 Sharp JT, Henry JP, Sweany SK, et al. The total work of breathing in normal and obese men. J Clin Invest 1964; 43: 728-739.

240 Weyland W, Schuhmann M, Rathgeber J, et al. Oxygen cost of breathing for assisted spontaneous breathing modes: investigation into three states of pulmonary function. Intensive Care Med 1995; 21: 211-217.

241 Schols AM, Soeters PB, Mostert R, et al. Energy balance in chronic obstructive pulmonary disease. Am Rev Respir Dis 1991; 143: 1248-1252.

242 Bell SC, Saunders MJ, Elborn JS, et al. Resting energy expenditure and oxygen cost of breathing in patients with cystic fibrosis. Thorax 1996; 51: 126-131.

243 Katsardis CV, Desmond KJ, Coates AL. Measuring the oxygen cost of breathing in normal adults and patients with cystic fibrosis. Respir Physiol 1986; 65: 257-266.

244 Thomas J, Enecio CE, Chehreh MN, et al. Oxygen cost of breathing III: studies in asthmatic children. J Natl Med Assoc 1976; 68: 374-377. 
Harden KA, Young RC Jr, Carr C, et al. Oxygen cost of breathing. II. Studies in patients with sarcoidosis. Am Rev Respir Dis 1968; 97: 1127-1130.

Kurotobi T, Sato H, Yokoyama H, et al. Respiratory oxygen cost for dead space challenge is characteristically increased during exercise in patients with chronic heart failure: does it further decrease exercise capacity? J Card Fail 1997; 3: 181-188.

Reddy HK, McElroy PA, Janicki JS, et al. Response in oxygen uptake and ventilation during stair climbing in patients with chronic heart failure. Am J Cardiol 1989; 63: 222-225. $174-180$.

Duiverman ML, Arellano-Maric MP, Windisch W. Long-term noninvasive ventilation in patients with chronic hypercapnic respiratory failure: assisting the diaphragm, but threatening the heart? Curr Opin Pulm Med 2016; 22: 130-137.

White DP, Criner GJ, Dreher M, et al. The role of noninvasive ventilation in the management and mitigation of exacerbations and hospital admissions/readmissions for the patient with moderate to severe COPD (multimedia activity). Chest 2015; 147: 1704-1705.

Lee CC, Mankodi D, Shaharyar S, et al. High flow nasal cannula versus conventional oxygen therapy and non-invasive ventilation in adults with acute hypoxemic respiratory failure: a systematic review. Respir Med 2016; 121: $100-108$

Jolliet P, Ouanes-Besbes L, Abroug F, et al. A multicenter randomized trial assessing the efficacy of helium/ oxygen in severe exacerbations of chronic obstructive pulmonary disease. Am J Respir Crit Care Med 2017; 195: 871-880.

Bieli C, Summermatter S, Boutellier U, et al. Respiratory muscle training improves respiratory muscle endurance but not exercise tolerance in children with cystic fibrosis. Pediatr Pulmonol 2017; 52: 331-336.

Dellweg D, Reissig K, Hoehn E, et al. Inspiratory muscle training during rehabilitation in successfully weaned hypercapnic patients with COPD. Respir Med 2017; 123: 116-123.

Spruit MA, Singh SJ, Garvey C, et al. An official American Thoracic Society/European Respiratory Society statement: key concepts and advances in pulmonary rehabilitation. Am J Respir Crit Care Med 2013; 188: e13-e64.

Barreiro E, de la Puente B, Minguella J, et al. Oxidative stress and respiratory muscle dysfunction in severe chronic obstructive pulmonary disease. Am J Respir Crit Care Med 2005; 171: 1116-1124.

Barreiro E, Ferrer D, Sanchez F, et al. Inflammatory cells and apoptosis in respiratory and limb muscles of patients with COPD. J Appl Physiol 2011; 111: 808-817.

Doucet $\mathrm{M}$, Debigare $\mathrm{R}$, Joanisse $\mathrm{DR}$, et al. Adaptation of the diaphragm and the vastus lateralis in mild-to-moderate COPD. Eur Respir J 2004; 24: 971-979.

Marin-Corral J, Minguella J, Ramirez-Sarmiento AL, et al. Oxidised proteins and superoxide anion production in the diaphragm of severe COPD patients. Eur Respir J 2009; 33: 1309-1319.

Rabinovich RA, Bastos R, Ardite E, et al. Mitochondrial dysfunction in COPD patients with low body mass index. Eur Respir J 2007; 29: 643-650.

Barreiro E, Coronell C, Lavina B, et al. Aging, sex differences, and oxidative stress in human respiratory and limb muscles. Free Radic Biol Med 2006; 41: 797-809.

Barreiro E, Nowinski A, Gea J, et al. Oxidative stress in the external intercostal muscles of patients with obstructive sleep apnoea. Thorax 2007; 62: 1095-1101.

Pascual-Guardia S, Arbol F, Sanchez E, et al. [Inflammation and oxidative stress in respiratory and limb muscles of patients with severe sepsis]. Med Clin 2013; 141: 194-200.

Pascual-Guardia S, Wodja E, Gorostiza A, et al. [Improvement in quality of life and exercise capacity without muscular biology changes after general training in patients with severe chronic obstructive pulmonary disease]. Med Clin 2013; 140: 200-206.

Pasto M, Gea J, Blanco M, et al. [Metabolic activity of the external intercostal muscle of patients with COPD]. Arch Bronconeumol 2001; 37: 108-114.

Maltais F, Decramer M, Casaburi R, et al. An official American Thoracic Society/European Respiratory Society statement: update on limb muscle dysfunction in chronic obstructive pulmonary disease. Am J Respir Crit Care Med 2014; 189: e15-e62.

Levine S, Kaiser L, Leferovich J, et al. Cellular adaptations in the diaphragm in chronic obstructive pulmonary disease. N Engl J Med 1997; 337: 1799-1806.

Levine S, Gregory C, Nguyen T, et al. Bioenergetic adaptation of individual human diaphragmatic myofibers to severe COPD. J Appl Physiol 2002; 92: 1205-1213.

Gea J, Hamid Q, Czaika G, et al. Expression of myosin heavy-chain isoforms in the respiratory muscles following inspiratory resistive breathing. Am J Respir Crit Care Med 2000; 161: 1274-1278. Crit Care Med 1997; 155: 1110-1116.

Orozco-Levi M, Gea J, Lloreta JL, et al. Subcellular adaptation of the human diaphragm in chronic obstructive pulmonary disease. Eur Respir J 1999; 13: 371-378.

2 Orozco-Levi M, Lloreta J, Minguella J, et al. Injury of the human diaphragm associated with exertion and chronic obstructive pulmonary disease. Am J Respir Crit Care Med 2001; 164: 1734-1739.

Engelen MP, Orozco-Levi M, Deutz NE, et al. Glutathione and glutamate levels in the diaphragm of patients with chronic obstructive pulmonary disease. Eur Respir J 2004; 23: 545-551.

Sanchez J, Derenne JP, Debesse B, et al. Typology of the respiratory muscles in normal men and in patients with moderate chronic respiratory diseases. Bull Eur Physiopathol Respir 1982; 18: 901-914.

Levine S, Nguyen T, Friscia M, et al. Parasternal intercostal muscle remodeling in severe chronic obstructive pulmonary disease. J Appl Physiol 2006; 101: 1297-1302.

Jimenez-Fuentes MA, Gea J, Aguar MC, et al. [Capillary density and respiratory function in the external intercostal muscle]. Arch Bronconeumol 1999; 35: 471-476.

Ju S, Lee SJ, Park MJ, et al. Clinical importance of cross-sectional area of intercostal muscles in patients with chronic obstructive pulmonary disease. Clin Respir J 2018; 12: 939-947. 

obstructive pulmonary disease: structural adaptation and physiologic outcomes. Am J Respir Crit Care Med 2002; 166: 1491-1497.

279 Jaber S, Petrof BJ, Jung B, et al. Rapidly progressive diaphragmatic weakness and injury during mechanical ventilation in humans. Am J Respir Crit Care Med 2011; 183: 364-371.

280 Levine S, Nguyen T, Taylor N, et al. Rapid disuse atrophy of diaphragm fibers in mechanically ventilated humans. N Engl J Med 2008; 358: 1327-1335.

281 Garcia-Cazarin ML, Gamboa JL, Andrade FH. Rat diaphragm mitochondria have lower intrinsic respiratory rates than mitochondria in limb muscles. Am J Physiol Regul Integr Comp Physiol 2011; 300: R1311-R1315.

282 Gamboa JL, Andrade FH. Mitochondrial content and distribution changes specific to mouse diaphragm after chronic normobaric hypoxia. Am J Physiol Regul Integr Comp Physiol 2010; 298: R575-R583.

283 Picard M, Godin R, Sinnreich M, et al. The mitochondrial phenotype of peripheral muscle in chronic obstructive pulmonary disease: disuse or dysfunction? Am J Respir Crit Care Med 2008; 178: 1040-1047.

284 Puente-Maestu L, Perez-Parra J, Godoy R, et al. Abnormal mitochondrial function in locomotor and respiratory muscles of COPD patients. Eur Respir J 2009; 33: 1045-1052.

285 Wijnhoven JH, Janssen AJ, van Kuppevelt TH, et al. Metabolic capacity of the diaphragm in patients with COPD. Respir Med 2006; 100: 1064-1071.

286 Ribera F, N'Guessan B, Zoll J, et al. Mitochondrial electron transport chain function is enhanced in inspiratory muscles of patients with chronic obstructive pulmonary disease. Am J Respir Crit Care Med 2003; 167: 873-879.

287 Fredriksson K, Rooyackers O. Mitochondrial function in sepsis: respiratory versus leg muscle. Crit Care Med 2007; 35: Suppl. 9, S449-S453.

288 Bernard N, Matecki S, Py G, et al. Effects of prolonged mechanical ventilation on respiratory muscle ultrastructure and mitochondrial respiration in rabbits. Intensive Care Med 2003; 29: 111-118.

289 Wijnhoven HJ, Ennen L, Rodenburg RJ, et al. Mitochondrial function in diaphragm of emphysematous hamsters after treatment with nandrolone. Int J Chron Obstruct Pulmon Dis 2006; 1: 83-89.

290 Powers SK, Criswell D. Adaptive strategies of respiratory muscles in response to endurance exercise. Med Sci Sports Exerc 1996; 28: 1115-1122.

291 Ottenheijm CA, Heunks LM, Li YP, et al. Activation of the ubiquitin-proteasome pathway in the diaphragm in chronic obstructive pulmonary disease. Am J Respir Crit Care Med 2006; 174: 997-1002.

292 Ottenheijm CA, Heunks LM, Sieck GC, et al. Diaphragm dysfunction in chronic obstructive pulmonary disease. Am J Respir Crit Care Med 2005; 172: 200-205.

293 Hussain SN, Mofarrahi M, Sigala I, et al. Mechanical ventilation-induced diaphragm disuse in humans triggers autophagy. Am J Respir Crit Care Med 2010; 182: 1377-1386.

294 Picard M, Jung B, Liang F, et al. Mitochondrial dysfunction and lipid accumulation in the human diaphragm during mechanical ventilation. Am J Respir Crit Care Med 2012; 186: 1140-1149.

295 Jaitovich A, Barreiro E. Skeletal muscle dysfunction in chronic obstructive pulmonary disease. What we know and can do for our patients. Am J Respir Crit Care Med 2018; 198: 175-186.

296 Casadevall C, Coronell C, Ramirez-Sarmiento AL, et al. Upregulation of pro-inflammatory cytokines in the intercostal muscles of COPD patients. Eur Respir J 2007; 30: 701-707.

297 Volianitis S, McConnell AK, Jones DA. Assessment of maximum inspiratory pressure. Prior submaximal respiratory muscle activity ('warm-up') enhances maximum inspiratory activity and attenuates the learning effect of repeated measurement. Respiration 2001; 68: 22-27.

298 Fiz JA, Montserrat JM, Picado C, et al. How many maneuvers should be done to measure maximal inspiratory mouth pressure in patients with chronic air-flow obstruction. Thorax 1989; 44: 419-421.

299 Lofaso F, Nicot F, Lejaille M, et al. Sniff nasal inspiratory pressure: what is the optimal number of sniffs? Eur Respir J 2006; 27: 980-982.

300 Terzi N, Corne F, Mouadil A, et al. Mouth and nasal inspiratory pressure: learning effect and reproducibility in healthy adults. Respiration 2010; 80: 379-386.

301 Bianchi C, Baiardi P. Cough peak flows: standard values for children and adolescents. Am J Phys Med Rehab 2008; 87: 461-467.

302 Bach JR, Saporito LR. Criteria for extubation and tracheostomy tube removal for patients with ventilatory failure a different approach to weaning. Chest 1996; 110: 1566-1571.

303 Miller JM, Moxham J, Green M. The maximal sniff in the assessment of diaphragm function in man. Clin Sci 1985; 69: 91-96.

304 Polkey MI, Harris ML, Hughes PD, et al. The contractile properties of the elderly human diaphragm. Am J Respir Crit Care Med 1997; 155: 1560-1564.

305 Hughes PD, Polkey MI, Harris ML, et al. Diaphragm strength in chronic heart failure. Am J Respir Crit Care Med 1999; 160: 529-534.

306 Kabitz HJ, Schwoerer A, Bremer HC, et al. Impairment of respiratory muscle function in pulmonary hypertension. Clin Sci 2008; 114: 165-171.

307 Hug F, Raux M, Prella M, et al. Optimized analysis of surface electromyograms of the scalenes during quiet breathing in humans. Respir Physiol Neurobiol 2006; 150: 75-81.

308 Chuang SY, Teng A, Butler JE, et al. Validation of a quantitative method to measure neural respiratory drive in children during sleep. Respir Physiol Neurobiol 2017; 239: 75-80.

309 Allen GM, McKenzie DK, Gandevia SC, et al. Reduced voluntary drive to breathe in asthmatic subjects. Respir Physiol 1993; 93: 29-40.

310 Hodges PW, Heijnen I, Gandevia SC. Postural activity of the diaphragm is reduced in humans when respiratory demand increases. J Physiol (Lond) 2001; 537: 999-1008.

311 Hodges PW, Gandevia SC. Pitfalls of intramuscular electromyographic recordings from the human costal diaphragm. Clin Neurophysiol 2000; 111: 1420-1424.

312 Luo YM, Polkey MI, Johnson LC, et al. Diaphragm EMG measured by cervical magnetic and electrical phrenic nerve stimulation. J Appl Physiol 1998; 85: 2089-2099.

313 McKenzie DK, Gandevia SC. Phrenic nerve conduction times and twitch pressures of the human diaphragm. $J$ Appl Physiol 1985; 58: 1496-1504. 
314 Chokroverty S, Hening W, Wright D, et al. Magnetic brain stimulation: safety studies. Electroencephalogr Clin Neurophysiol 1995; 97: 36-42.

315 Ngomo S, Leonard G, Moffet H, et al. Comparison of transcranial magnetic stimulation measures obtained at rest and under active conditions and their reliability. J Neurosci Methods 2012; 205: 65-71.

316 Malcolm MP, Triggs WJ, Light KE, et al. Reliability of motor cortex transcranial magnetic stimulation in four muscle representations. Clin Neurophysiol 2006; 117: 1037-1046.

317 Kimberley TJ, Borich MR, Prochaska KD, et al. Establishing the definition and inter-rater reliability of cortical silent period calculation in subjects with focal hand dystonia and healthy controls. Neurosci Lett 2009; 464: $84-87$.

318 Flitman SS, Grafman J, Wassermann EM, et al. Linguistic processing during repetitive transcranial magnetic stimulation. Neurology 1998; 50: 175-181. 